\title{
Extratropical Influence on 200-hPa Easterly Acceleration over the Western Indian Ocean Preceding Madden-Julian Oscillation Convective Onset
}

\author{
JENNIFER GAHTAN AND PAUL ROUNDY \\ Department of Atmospheric and Environmental Sciences, University at Albany, State University of New York, Albany, New York
}

(Manuscript received 27 February 2018, in final form 20 September 2018)

\begin{abstract}
The onset of Madden-Julian oscillation (MJO) deep convection often occurs over the western Indian Ocean and has upper-tropospheric circulation precursors that consist of eastward-circumnavigating tropical easterlies and subtropical cyclonic Rossby gyres near eastern Africa. Moreover, the evolution of the largescale circulation and its ability to reduce subsidence may be necessary for the initial development of organized deep convection. To better understand the evolution of the circulation precursors and their interaction with convective onset, this paper analyzes the upper-tropospheric zonal momentum budget using a regional index based on the temporal progression of the meridional structure of intraseasonal outgoing longwave radiation anomalies over eastern Africa and the western Indian Ocean. The circumnavigating intraseasonal easterly acceleration produces upper-level divergence when it reaches the western extent of a region of intraseasonal westerlies and may provide a forcing for the in-phase midtropospheric upward vertical motion. For about three-quarters of the identified cases, the easterly acceleration over the western Indian Ocean is a response to the zonal pressure gradient over the region. In the composite, the negative pressure gradient force may be initially induced by the injection of negative geopotential height anomalies from the extratropics of both hemispheres to the tropics over eastern Africa, though tropically circumnavigating and local signals may also contribute to the easterly acceleration, especially in the days following convective onset.
\end{abstract}

\section{Introduction}

The Madden-Julian oscillation (MJO; Zhang 2005) is typically characterized by equatorial eastward-propagating circulative and deep convective anomalies on intraseasonal temporal and planetary zonal scales. While circulation signals extend globally, MJO deep convection is mainly restricted to tropical warm pool regions, such that convective onset often occurs over the western Indian Ocean. Though discharge-recharge-type hypotheses suggest that the moistening required for onset may be achieved locally (Bladé and Hartmann 1993; Benedict and Randall 2007; etc.), observational studies in the DYNAMO field campaign (Powell and Houze 2013, 2015) and for convection in general (Hohenegger and Stevens 2012) suggest that cumulus congestus clouds are insufficient for moistening and the large-scale circulation needs to be favorable for deep convection to form.

Prior to onset, the observed evolution of intraseasonal large-scale dynamics includes eastward-circumnavigating upper-level easterly winds in the tropics over the Western

\footnotetext{
Corresponding author: Jennifer Gahtan, jgahtan@albany.edu
}

Hemisphere (Straub 2013; Roundy 2014) and a transition in subtropical upper-tropospheric Rossby gyres from cyclonic to anticyclonic in the regions near eastern Africa. While the easterly winds in the tropics propagate eastward, easterly acceleration over the east Pacific is not forced by a Kelvin wave but instead driven by intrusions from the extratropics and equatorial Rossby waves (Sakaeda and Roundy 2015, 2016), such that the circumnavigating tropical and extratropical signals may not be independent from one another over the Western Hemisphere. In the subtropics near eastern Africa, upperlevel cyclonic (lower-level anticyclonic) Rossby gyre precursors may be initially forced by MJO-suppressed latent heating along the equator, analogous to the Gill model's response to a stationary heat source in the tropics (Gill 1980; Barlow et al. 2005, 2007). Conversely, the Rossby gyres also phase with extratropical intraseasonal wave trains that may have a role in their development (e.g., Hsu et al. 1990). Nevertheless, the gyres cannot be treated as stationary features like in the Gill model, because they are associated with propagating convective anomalies. At lower levels, the anticyclonic Rossby gyres help to moisten the lower troposphere leading up to MJO onset 
(Zhao et al. 2013). These transitioning large-scale dynamics may help to reduce subsidence over the western Indian Ocean, such that external forcing from extratropical wave trains and circumnavigating equatorial Kelvin waves are both proposed as potential triggers for convection.

To test the impact of external forcings on the MJO, a variety of modeling mechanism studies block external forcings from either the extratropics or the Atlantic Ocean, using full global climate models (Zhao et al. 2013; Ray and Li 2013; Ma and Kuang 2016), tropical channel models (Ray and Zhang 2010; Ray et al. 2011; Hall et al. 2017), regional models (Zhang et al. 2017), or aquaplanet simulations (Maloney and Wolding 2015). The imposed boundaries may impact the mean state in the models, however, some of the more recent studies take steps to accurately reproduce the mean state by only removing intraseasonally filtered signals (Hall et al. 2017) or MJO-filtered signals (Zhang et al. 2017); another approach nudges a model with low-frequency forcings to maintain the mean-state conditions (Ma and Kuang 2016). Overall, these studies maintain disagreement on the importance of external forcings: Some studies find extratropical signals to be essential for either MJO onset or amplitude (Ray and Zhang 2010; Ray et al. 2011; Zhao et al. 2013; Ray and Li 2013; Hall et al. 2017), others highlight the importance of circumnavigating signals (Maloney and Wolding 2015; Zhang et al. 2017), and another study determines that preventing interaction with the extratropics and the Atlantic does not hinder the organization of MJO convection, as long as the mean state is maintained (Ma and Kuang 2016).

Further modeling studies have forced tropical signals by introducing disturbances into the extratropics. In a dry model with realistic zonal mean flow, Lin et al. (2007) found that Rossby-type forcings in the extratropics generate an MJO-type signal by inducing a Kelvin wave response in the tropics. Pan and Li (2008) introduce a vorticity perturbation at $45^{\circ} \mathrm{N}, 20^{\circ} \mathrm{E}$ to a baroclinic 2.5-layer model and see southeastward propagation of the disturbance and subsequent MJO initiation on the equator.

Observational studies also suggest a role for the extratropics. In composites, increased high-frequency transients move from the southwest Asian subtropical jet toward the equatorial Indian Ocean during periods when MJO convection is incipient (Matthews and Kiladis 1999). For an MJO case in 1986/87, MJO deep convection organizes after a wave pattern over the northern Atlantic Ocean reaches the Indian Ocean (Hsu et al. 1990). In several cases, cold surges from west Asia are proposed to help initiate MJO deep convection (Wang et al. 2012), while MJO-induced extratropical circulation anomalies may make conditions more favorable for cold surges to occur (Jeong et al. 2005). The extratropics are also shown to provide intraseasonal kinetic energy to the MJO for some events (Zhou et al. 2012).

While these studies and others highlight potential influences of the extratropics on convective onset, the role of these tropical-extratropical interactions in the evolution of upper-tropospheric zonal momentum over the western Indian Ocean has yet to be determined.

Moreover, while our interest in the MJO is over the western Indian Ocean, signals associated with the MJO have been preferentially studied over warm pool regions. Commonly used longitudinal empirical orthogonal function (EOF) identification techniques, including the real-time multivariate MJO (RMM) index (Wheeler and Hendon 2004) and the outgoing longwave radiation (OLR) MJO index (OMI; Kiladis et al. 2014) are either dominated by global circulation signals (Straub 2013) or by warm pool convection, neither of which adequately resolve signals associated with the MJO close to Africa. Wavenumber-frequency filtering of OLR may also struggle to include information over the region of interest; for example, it fails to detect MJO-associated OLR signals over Africa for events in the winter of 1992/93 (Straub 2013).

Instead of global identification techniques, an index based on the temporal evolution of the latitudinal structure in intraseasonal OLR near eastern Africa and the western Indian Ocean provides a regional focus and highlights local tropical-extratropical interactions. Analysis of the zonal momentum budget over the western Indian Ocean diagnoses forcings responsible for the easterly acceleration of upper-level winds around the time of convective onset.

\section{Data and methods}

\section{a. Data}

OLR data from the National Oceanic and Atmospheric Administration (NOAA) are used on a $2.5^{\circ}$ grid as a proxy for convection (Liebmann and Smith 1996). To determine dynamical interactions, ECMWF ReAnalysis (ERA)-Interim horizontal and vertical velocity, geopotential height, and temperature data are used (Dee et al. 2011). Reanalysis data are analyzed on a $512 \times 256$ Gaussian global grid. The period of analysis is from 1979 to 2012, daily.

To find anomalies from climatology, the annual cycle and its first three harmonics are subtracted using the climatology from 1979 to 2012. To isolate intraseasonal time 


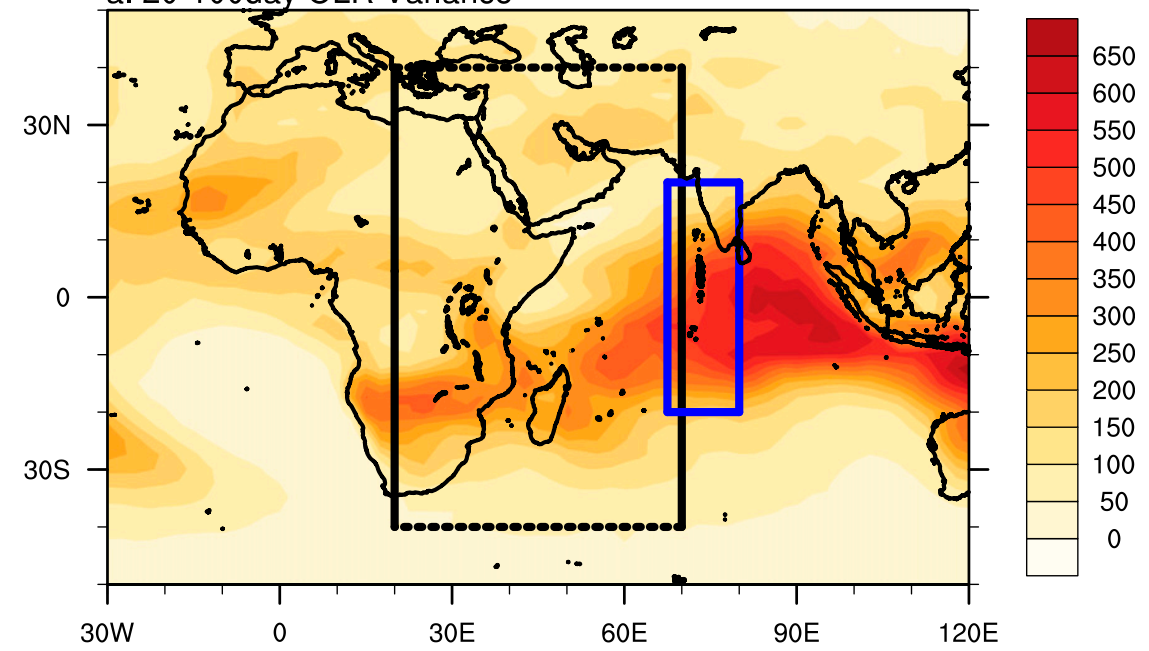

b. 20-100day U Variance

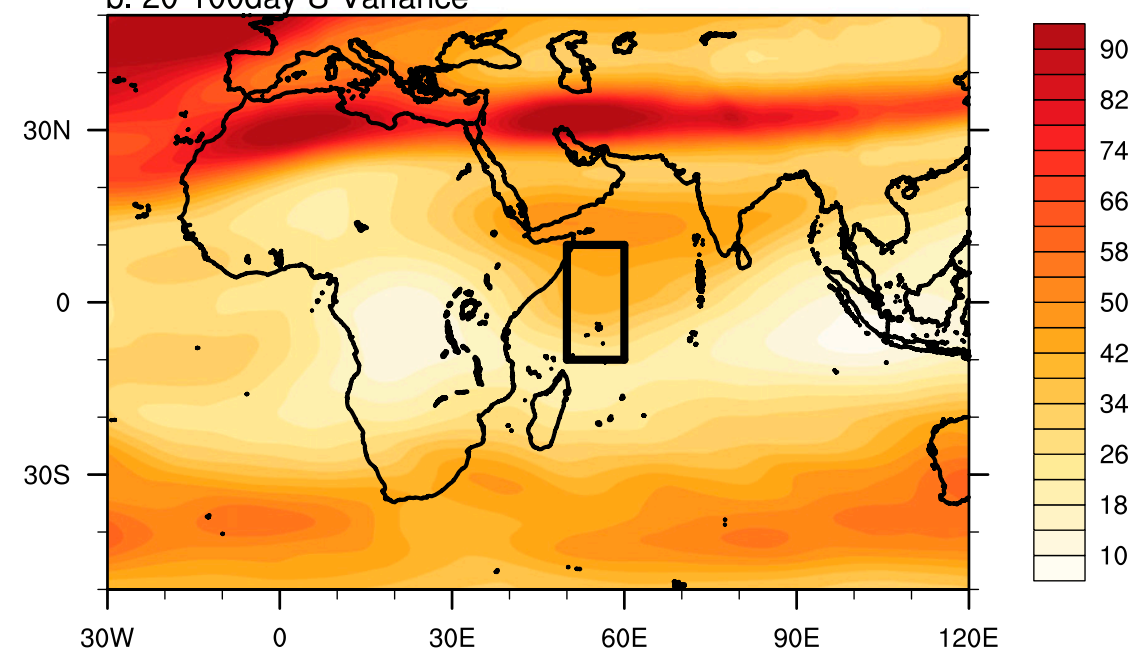

FIG. 1. (a) 20-100-day OLR $\left(\mathrm{W}^{2} \mathrm{~m}^{-4}\right)$ and (b) zonal wind $\left(\mathrm{m}^{2} \mathrm{~s}^{-2}\right)$ variance from November to April. Longitudinal boundaries of the index region from $20^{\circ}$ to $70^{\circ} \mathrm{E}$ are shown in solid black lines in (a). Data within the region of interest are selected from $40^{\circ} \mathrm{S}$ to $40^{\circ} \mathrm{N}$ of the seasonal cycle latitudinal center of 20-100-day OLR variance in the latitudinal centering region $67.5^{\circ}-$ $80^{\circ} \mathrm{E}$, shown in blue. The zonal momentum budget is calculated for the black box in (b).

scales, data are filtered for 20-100 days using Lanczos filters with 201 weights (Duchon 1979).

Even though OLR variability is small in the subtropics near eastern Africa in comparison with variability in the tropics, distinct signals appear in the intraseasonal OLR field (Fig. 1a), such that we can use these data to trace the upper-tropospheric wave and circulation activity. These OLR anomalies should not necessarily be interpreted as deep moist convection over the subtropics, yet corresponding signals show up in other data fields including upper-tropospheric water vapor (Schreck et al. 2013), further justifying their use. Though other fields besides OLR may be easier to directly interpret, OLR proves to be sufficient in identifying corresponding dynamical signals and is advantageous in its long period of availability and independence from modeled reanalysis data.

\section{b. Event identification}

The intraseasonal OLR data are selected from $20^{\circ}$ to $70^{\circ} \mathrm{E}$, over an area including eastern Africa, southwest Asia, and the western Indian Ocean (black box in Fig. 1a). To identify commonly occurring patterns of intraseasonal movement of OLR in the meridional direction, time-extended latitudinal EOFs of the intraseasonal OLR are calculated.

Before the EOFs are computed, the data are latitudinally recentered throughout the year to account for the 
seasonal cycle fluctuation of intraseasonal convective activity over eastern Africa (Hogan et al. 2015). The region used to recenter is between $67.5^{\circ}$ and $80^{\circ} \mathrm{E}$, as subtropical Rossby gyres in the region are influenced by MJO deep convection over the Indian Ocean (Barlow et al. 2007), plus the seasonal cycle maintains a closer distance to the equator without a large northward shift during boreal summer (blue box in Fig. 1a; see also Fig. 2) as compared to the region from $20^{\circ}$ to $70^{\circ} \mathrm{E}$ (not shown). To recenter, we compute the annual cycle of the variance of the intraseasonal OLR using the primary harmonic. Subsequently, the daily climatological latitudinal maxima of intraseasonal OLR variance within the region between $20^{\circ} \mathrm{S}$ and $20^{\circ} \mathrm{N}$ are found for each longitudinal step from $67.5^{\circ}$ to $80^{\circ} \mathrm{E}$. These values are averaged over all longitudinal grid points in the centering region and a smoothed seasonal cycle including the first harmonic is calculated (black line in Fig. 2).

The regional intraseasonal OLR data are placed into latitude by lag-time matrices including data spanning from $40^{\circ}$ north of to $40^{\circ}$ south of the seasonal cycle center latitudes and occurring from 25 days before to 25 days after every day. We perform two-dimensional EOF analysis on the data matrices. The EOFs represent commonly occurring temporally evolving latitudinal structures of the intraseasonal OLR over the region and are shown after rotation to match RMM as described later in this section (Fig. 3). The leading spatial-temporal pattern shows anomalous OLR signals present in the subtropics about 10 days prior to those of the same sign in the tropics. Anomalies over the Northern Hemisphere have a strong center near $30^{\circ} \mathrm{N}$, which weakens before strengthening again closer to the equator, whereas the Southern Hemisphere anomalies have a much weaker center just south of $25^{\circ} \mathrm{S}$ but maintain their amplitude as they move equatorward. Perturbations of one sign last for around 20 days for both the tropics and the subtropics. The second EOF has patterns consistent with the first EOF but rotated $90^{\circ}$ out of phase in both lag time and space.

Principal components (PCs) are calculated by projecting daily data onto the individual EOF patterns. Each principal component is then divided by its standard deviation for scaling purposes. $\mathrm{PC} 1$ accounts for $11.2 \%$ and $\mathrm{PC} 2$ accounts for $11.5 \%$ of the variance after rotation to best match the RMM index (discussed below). These levels of variance are well separated from the third $\mathrm{PC}$, which is responsible for $\sim 5 \%$ of the variance, as per the criteria of North et al. (1982). The leading two principal components are also approximately $90^{\circ}$ out of phase with one another (example period shown in Fig. 4a); together with the evolution of the spatial structure, this indicates a propagating pattern of intraseasonal OLR anomalies shifting from the subtropics to the tropics.

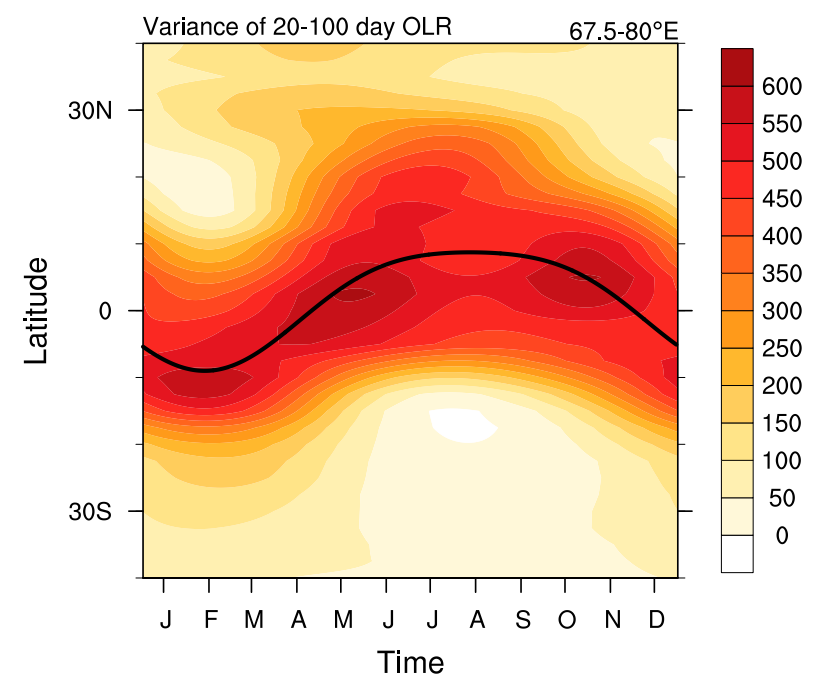

FIG. 2. Seasonal cycle of the variance of 20-100-day OLR averaged over the centering region from $67.5^{\circ}$ to $80^{\circ} \mathrm{E}\left(\mathrm{W}^{2} \mathrm{~m}^{-4}\right)$. The black line shows the seasonal cycle of latitude of maximum intraseasonal OLR variance smoothed using one harmonic and is used to recenter latitudes for the regional EOFs.

To ease comparison, the leading two principal components are rotated to best match those of the widely used RMM index (Wheeler and Hendon 2004), through the use of a rotation matrix. The relationship between the leading two PCs is manipulated to form a phase space subdivided into eight sections, following Wheeler and Hendon (2004). The choice to represent the index in phases rotated to match the RMM index adheres to commonly used convention in existing literature and demonstrates when local signals are in phase with global ones.

Though wavenumber filtering is not explicitly applied in the creation of the index, averaging over a $50^{\circ}$ longitude region dictates that the detected disturbances have anomalies of like sign for this and larger zonal expanses (consistent with extents between zonal wavenumbers 3 and 4 , as well as lower wavenumbers). As the MJO shows up in wavenumber-frequency power spectra for wavenumbers 1-5 (Wheeler and Kiladis 1999), this algorithm identifies disturbances of the desired dimensions while eliminating those with smaller zonal scales without wavenumber filtering. However, because of the 20-100-day filtering and time extension of the EOFs, time scales of identified events are constrained and results may not apply to all MJO events.

Subtle changes in choices made in the identification process do not greatly impact the ensuing interpretation. Henceforward, this index is referred to as the intraseasonal meridional mode index (IMMI).

\section{c. Analysis of composites}

Composites shown hereafter are relative to IMMI phase 1, when low OLR anomalies are beginning to 


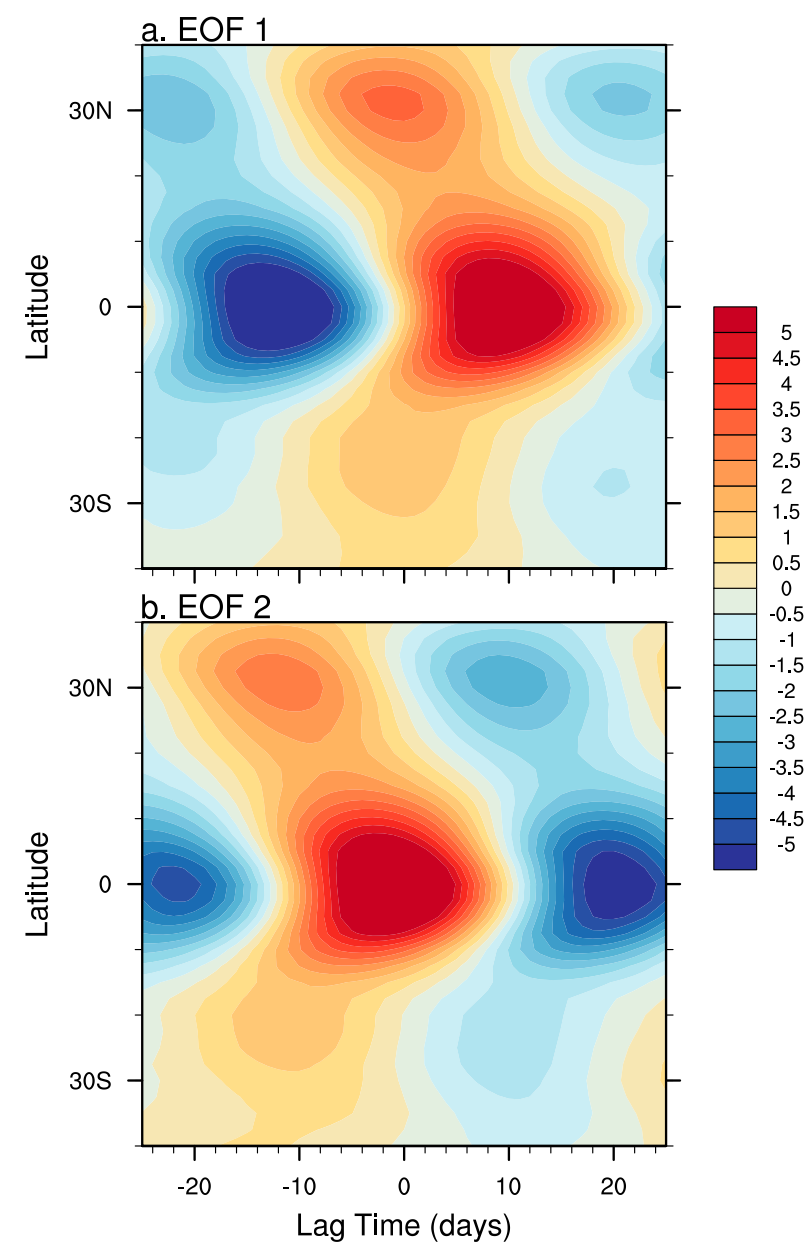

FIG. 3. Structure of the leading two time-extended latitudinal EOFs of the recentered 20-100-day OLR averaged from $20^{\circ}$ to $70^{\circ} \mathrm{E}$, which have been rotated with one another to achieve maximum correlation with the RMM PCs. Patterns have been normalized by the global variance of the intraseasonal OLR and are thus in units of $\mathrm{W} \mathrm{m}^{-2}$. (a) EOF1 represents $11.2 \%$ and (b) EOF2 $11.5 \%$ of the variance within the latitude-lag field after rotation to match RMM.

form over the western Indian Ocean during the months of November-April (shown in Fig. 6f). Individual events selected have amplitudes above one standard deviation from climatology in order to capture more robust signals. Since the number of days an MJO event stays in a specific phase varies for each case, only one day per event is selected in order to not bias results toward events that lasted longer. For each event, we choose a day for the composite based on the angle between PC1 and $\mathrm{PC} 2$ in the phase space. For each day that meets the amplitude and phase 1 criteria, if there are any days with sufficient amplitude that have an angle closer to the center angle of phase 1 within the period from 10 days before to 10 days after that day, the day is removed from the composite. Since the principal components are a. Regional Index (IMMI)
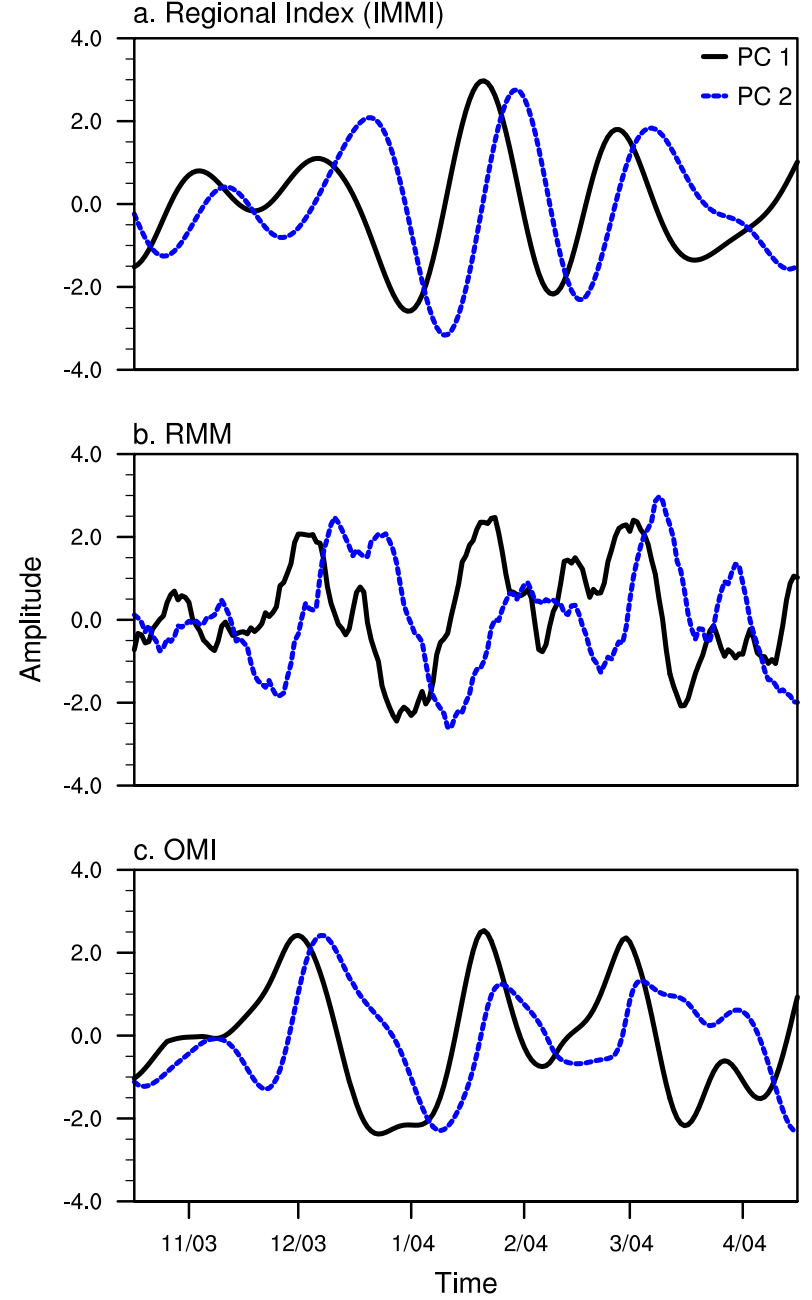

FIG. 4. Time series of the sets of leading two PCs used for (a) the regional index (IMMI), (b) RMM, and (c) OMI from November 2003 through April 2004.

relatively smooth because of the 20-100-day filter and EOF time extension, no additional criteria for continuity of events through later phases are required. The algorithms have selected a total of 84 separate events from November 1979 through April 2012. Events chosen with the RMM index in a similar manner are used for field comparisons; there are 94 individual RMM events given the above composite constraints. OMI (Kiladis et al. 2014) is also compared statistically to both IMMI and RMM, though no composites are shown. Events are divided into subsets based on the sign of different zonal momentum budget terms at lag zero.

Statistical significance is verified through the use of bootstrap testing in a manner similar to Schreck et al. (2013). We select null case samples of the same number of events as our composites that consist of dates from the climatology with the same month and day but different 

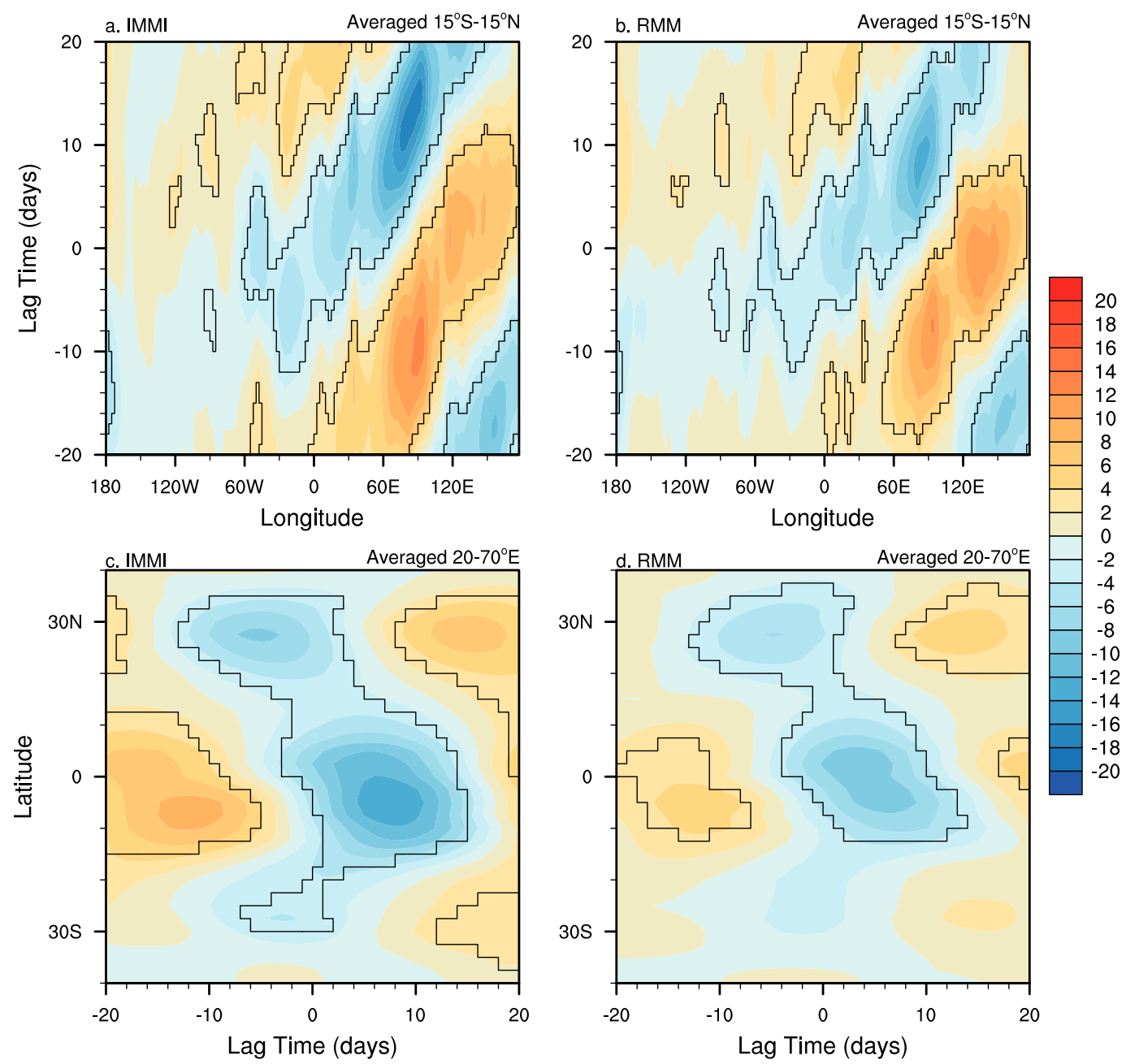

FIG. 5. (a),(b) Lag time vs longitude (averaged over $15^{\circ} \mathrm{S}-15^{\circ} \mathrm{N}$ ) and (c),(d) latitude vs lag-time (averaged over $\left.20^{\circ}-70^{\circ} \mathrm{E}\right)$ diagrams of intraseasonal OLR anomalies $\left(\mathrm{W} \mathrm{m}^{-2}\right)$ centered on phase 1 for events during NovemberApril using (a),(c) IMMI and (b),(d) RMM. Contours show where results are significant at the $95 \%$ level.

years from events in the composite. Each group of samples is averaged together and the resampling algorithm is repeated 1000 times. Signals are considered significant at the $95 \%$ level in a two-sided test if 975 of the null sample averages are either all less than or all greater than the event composite. Vectors are considered significant if either component is significant.

By finding a null distribution instead of an event resampling distribution, we may select null events with base states in which the events do not occur, and widen the effective testing distribution, making the bootstrap test more restrictive. Significance derived from this version of the bootstrap is valid; however, the chance of getting a false positive result is decreased, while the likelihood of getting a false negative is increased.

Full field significance is established by testing the average of the absolute values of the covariance matrix for a composite field against resampled averages of the absolute values of the covariance matrix for climatological composites selected in the same manner described above. Before calculating the covariance matrices, anomalies from climatology of the data are taken and the fields are weighted by the square root of the cosine of the latitude. Here, fields are considered significant at the $95 \%$ level if 950 of the null average absolute covariance values are less than composite average absolute covariance as this is a one-sided test. Field significance is tested for all fields shown at lag zero over the area shown in the map plot. All spatial fields displayed meet these criteria.

\section{d. Zonal momentum budget}

The zonal momentum budget is given by

$$
u_{t}=-\mathbf{v} \cdot \nabla u-\Phi_{x}+f v+X,
$$



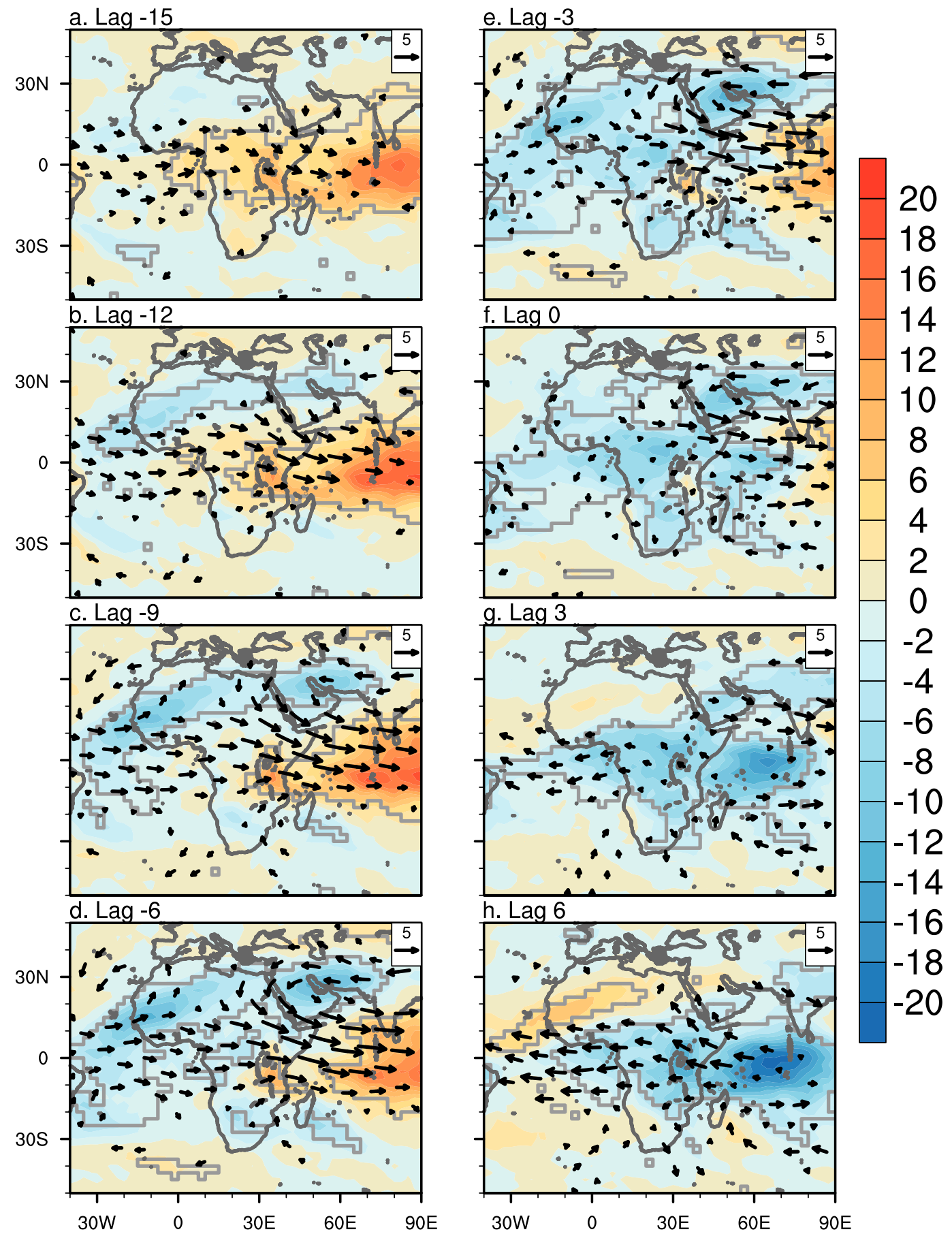

FIG. 6. Intraseasonal OLR (shading; $\mathrm{W} \mathrm{m}^{-2}$ ) and 200-hPa wind anomalies (vectors; $\mathrm{m} \mathrm{s}^{-1}$ ) at lags of (a) -15 , (b) -12 , (c) -9 , (d) -6, (e) -3, (f) 0, (g) 3, and (h) 6 days to IMMI phase 1. Gray contours (OLR) and the presence of vectors (wind) show where values are significant at the $95 \%$ level.

where $u$ is the zonal wind; subscripts represent partial derivatives; $\mathbf{v}$ comprises the zonal, meridional, and vertical velocities; $\nabla$ is the gradient; $\Phi$ is the geopotential; $f$ is the Coriolis parameter; $X$ is the residual term including diabatic processes; and all terms are in isobaric coordinates calculated at $200 \mathrm{hPa}$. To understand which terms contribute to changes in the zonal momentum on intraseasonal time scales, all terms are filtered for 20-100 days using a Lanczos filter with 201 weights. Horizontal derivatives are calculated using 
spherical harmonics, while temporal and vertical derivatives are calculated using a two-point centered finite difference scheme.

\section{e. $Q$ vectors}

The $\mathrm{Q}$ vector is a diagnostic for dynamically forced regions of upward motion in quasi geostrophy (Hoskins et al. 1978) where results may be generalized to the subtropics by the use of the quasi-geostrophic formulation with nondivergent (rotational) winds instead of the geostrophic winds (Davies-Jones 1991). Similar formulations of $\mathrm{Q}$ vectors have been effectively used in the contexts of African easterly waves (Kiladis et al. 2006), tropical cyclogenesis (McTaggart-Cowan et al. 2008), and a subtropical cyclonic gyre (Molinari and Vollaro 2012), among others. In this study, we use the quasigeostrophic $\mathrm{Q}$ vector with nondivergent winds following the formulation of Molinari and Vollaro (2012), where the $\mathrm{Q}$ vectors are given by

$$
\mathbf{Q}=\left(Q_{1}, Q_{2}\right)=-\frac{R}{p}\left[\left(\mathbf{v}_{\psi}\right)_{x} \cdot \nabla T,\left(\mathbf{v}_{\psi}\right)_{y} \cdot \nabla T\right] .
$$

The vertical velocity is then proportional to the divergence of the Q vector (Hoskins et al. 1978), such that Q-vector convergence provides a forcing for upward motion. We calculate $\mathrm{Q}$ vectors averaged from 400 to $200 \mathrm{hPa}$, then spatially smooth and filter them for time scales of 20-100 days, before calculating the Q-vector divergence. We choose the levels averaged between 400 and $200 \mathrm{hPa}$ as this is the layer just below the level where the momentum budget is taken and these levels have been used in previous literature (McTaggart-Cowan et al. 2008; Molinari and Vollaro 2012).

\section{Results}

\section{a. Comparison of indices}

Figure 4 shows time series of the sets of two principal components used for IMMI (Fig. 4a), RMM (Fig. 4b), and OMI (Fig. 4c) from November 2003 through April 2004. The set of PCs for IMMI are mainly in phase with both RMM and OMI, but with some key differences, as expected for an index based on local signals. Differences between IMMI and the traditional MJO indices may relate to structural variance in $\mathrm{MJO}$ signal in the target region or to non-MJO signals in one or more of the indices. Both IMMI and OMI are smoother than RMM because of the inherent 20-100-day filter used for the data. To illustrate the validity and advantages of the regional index, we provide a general statistical analysis of IMMI, RMM, and OMI as well as an OLR field comparison of IMMI with RMM.

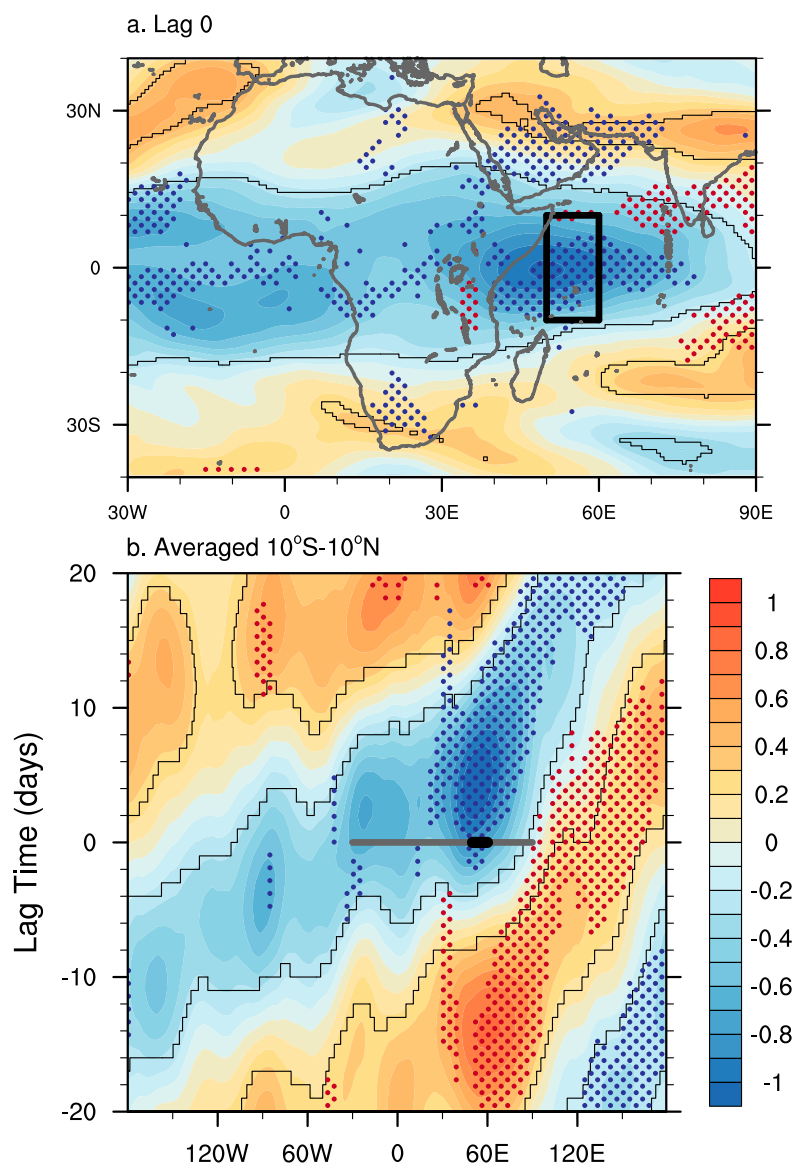

FIG. 7. IMMI composite (a) at lag zero and (b) as a lag time vs longitude diagram of the intraseasonal time tendency of the $200-\mathrm{hPa}$ zonal momentum $\left(10^{-5} \mathrm{~m} \mathrm{~s}^{-2}\right.$; shading) and the $500-\mathrm{hPa}$ vertical velocity $\left(\mathrm{hPa} \mathrm{s}^{-1}\right)$ shown as positive or negative in the dots. Temporal evolution of terms is analyzed within the $10^{\circ} \mathrm{S}-10^{\circ} \mathrm{N}, 50^{\circ}-60^{\circ} \mathrm{E}$ black box shown in (a) to contain the largest tendency signal at lag zero. The gray line in (b) represents the longitudes shown in (a), and the black line corresponds to the box. Contours (tendency) and the presence of dots (vertical velocity) show where values are significant at the $95 \%$ level. The $500-\mathrm{hPa}$ vertical velocity field is significant from $30^{\circ} \mathrm{S}$ to $30^{\circ} \mathrm{N}$.

\section{1) STATISTICAL COMPARISON OF INDICES}

During November-April, the maximum bivariate correlation of IMMI with RMM is 0.63 , with IMMI 1 day ahead of RMM (maximum bivariate correlation occurs with no lag when the whole year is included). These bivariate correlations are less than those between RMM and OMI, which maximize at 0.74 from November through April with OMI 1 day before RMM. Because of the inherent intraseasonal filtering in both IMMI and OMI, their correlations are stronger than IMMI and RMM, with values of 0.71 for November-April with IMMI 1 day before OMI.

While IMMI maintains relatively high correlations with RMM (and OMI), the indices are correlated because the regional meridional patterns tend to evolve 
with the zonally evolving structures in the RMM index not because the zonally evolving structures project directly onto the index. Thus, specific phases of the index cannot be directly linked with longitudinal locations of convection or circulation apart from eastern Africa and the western Indian Ocean.

\section{2) FIELD COMPARISON OF INDICES}

Time versus longitude composites for IMMI show continuous eastward-propagating convective signals over the tropics from $15^{\circ} \mathrm{S}$ to $15^{\circ} \mathrm{N}$ (Fig. 5a), verifying that the regional index selects events that also have global MJO structures. Strength and coherence of the IMMI equatorial enhanced convective signals are stronger than those of RMM (Fig. 5b), though positive OLR anomalies over the west Pacific are larger for RMM near lag zero.

Between $20^{\circ}$ and $70^{\circ} \mathrm{E}$, subtropical negative OLR anomalies present at lag -10 days shift toward the equator around lag zero, generally consistent with the structures identified in the IMMI EOFs (Figs. 3, 5c,d). Compared to IMMI, RMM composites have smaller amplitudes of signal over the selected region and less coherent signal coming from the Southern Hemisphere (Figs. 5c,d).

\section{b. IMMI structure of OLR and 200-hPa winds}

Fifteen days before lag zero, positive intraseasonal OLR anomalies dominate the Indian Ocean, consistent with the timing of the suppressed convective phase of the MJO (Fig. 6a). Negative OLR anomalies form over the subtropics near Africa about 12 days before lag zero (Fig. 6b). The positive tropical OLR anomalies move eastward, whereas the subtropical anomalies expand equatorward in the region of the western Indian Ocean, leading to negative OLR anomalies forming over central Africa between 6 and 3 days before lag zero (Figs. 6d,e). At lag zero, negative OLR anomalies are present along three separate latitudes over the western Indian Ocean and eastern Africa: centered near the equator, around $25^{\circ} \mathrm{N}$, and $20^{\circ} \mathrm{S}$ (Fig. 6f). Six days after lag zero, negative OLR anomalies are focused in the tropics of the Indian Ocean (Fig. 6h).

Leading up to lag zero, $200-\mathrm{hPa}$ intraseasonal wind anomalies are westerly in the tropics (Figs. 6a-e) with cyclonic motion in the subtropics near southwest Asia (Figs. 6c-f). Just after lag zero, 200-hPa equatorial winds anomalies switch from westerly to easterly over Africa and the western Indian Ocean, allowing for convective outflow and subtropical upper-tropospheric wind anomalies switch from equatorward-westerly to poleward-easterly as part of a transition from cyclonic to anticyclonic gyres (Figs. 6g,h).

\section{c. Zonal momentum budget}

The time tendency of intraseasonal zonal momentum shows globally circumnavigating tropical easterly wind

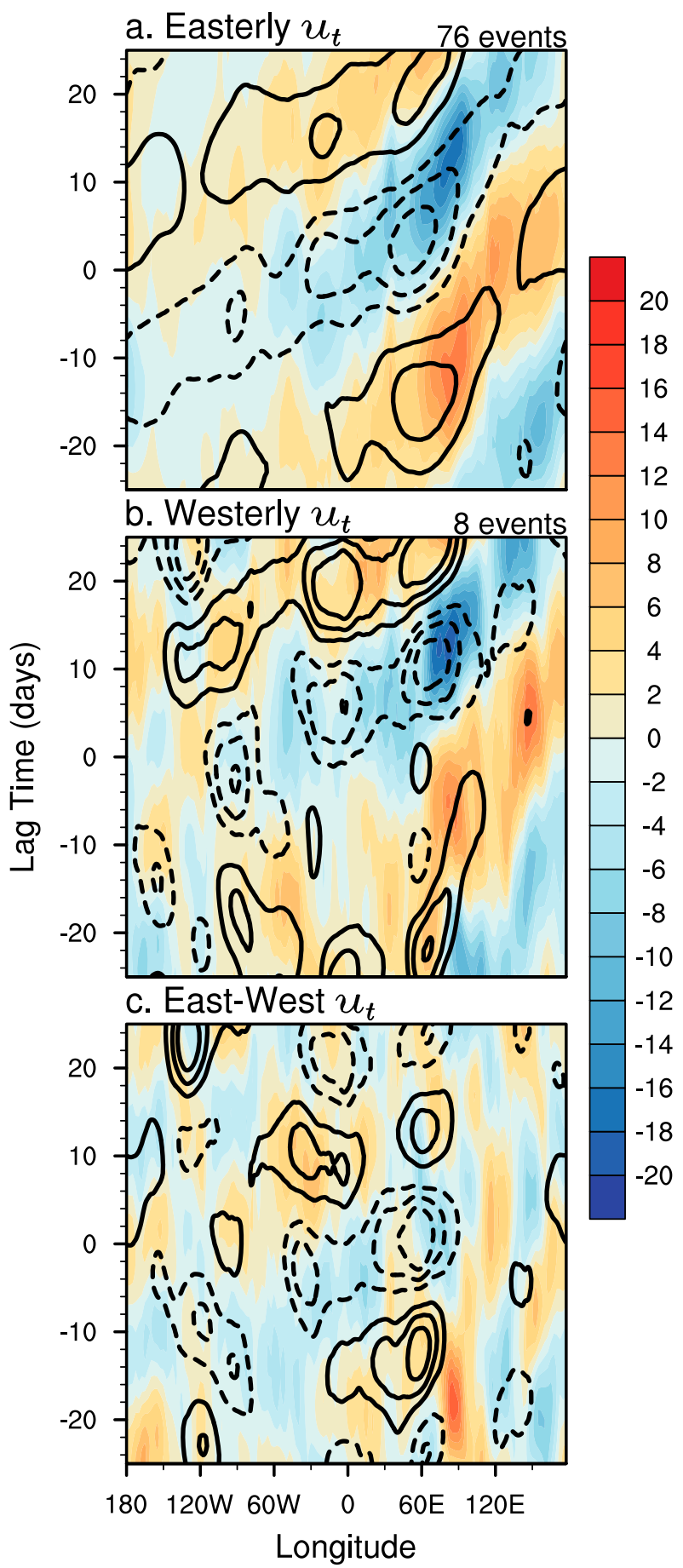

FIG. 8. IMMI lag time vs longitude composites of 20-100-day OLR (shading) and 200-hPa zonal momentum time tendency (contours) for events where the zonal momentum tendency is (a) negative and (b) positive, and (c) for their difference at lag zero over $10^{\circ} \mathrm{S}-10^{\circ} \mathrm{N}, 50-60^{\circ} \mathrm{E}$. Contours are from $-9 \times 10^{-6}$ to $+9 \times 10^{-6} \mathrm{~m} \mathrm{~s}^{-2}$ with an interval of $3 \times 10^{-6} \mathrm{~m} \mathrm{~s}^{-2}$, no contours at $0 \times 10^{-6} \mathrm{~m} \mathrm{~s}^{-2}$, and easterly tendency in dashes. Significance is not tested because of the small sample size of the westerly tendency events. 

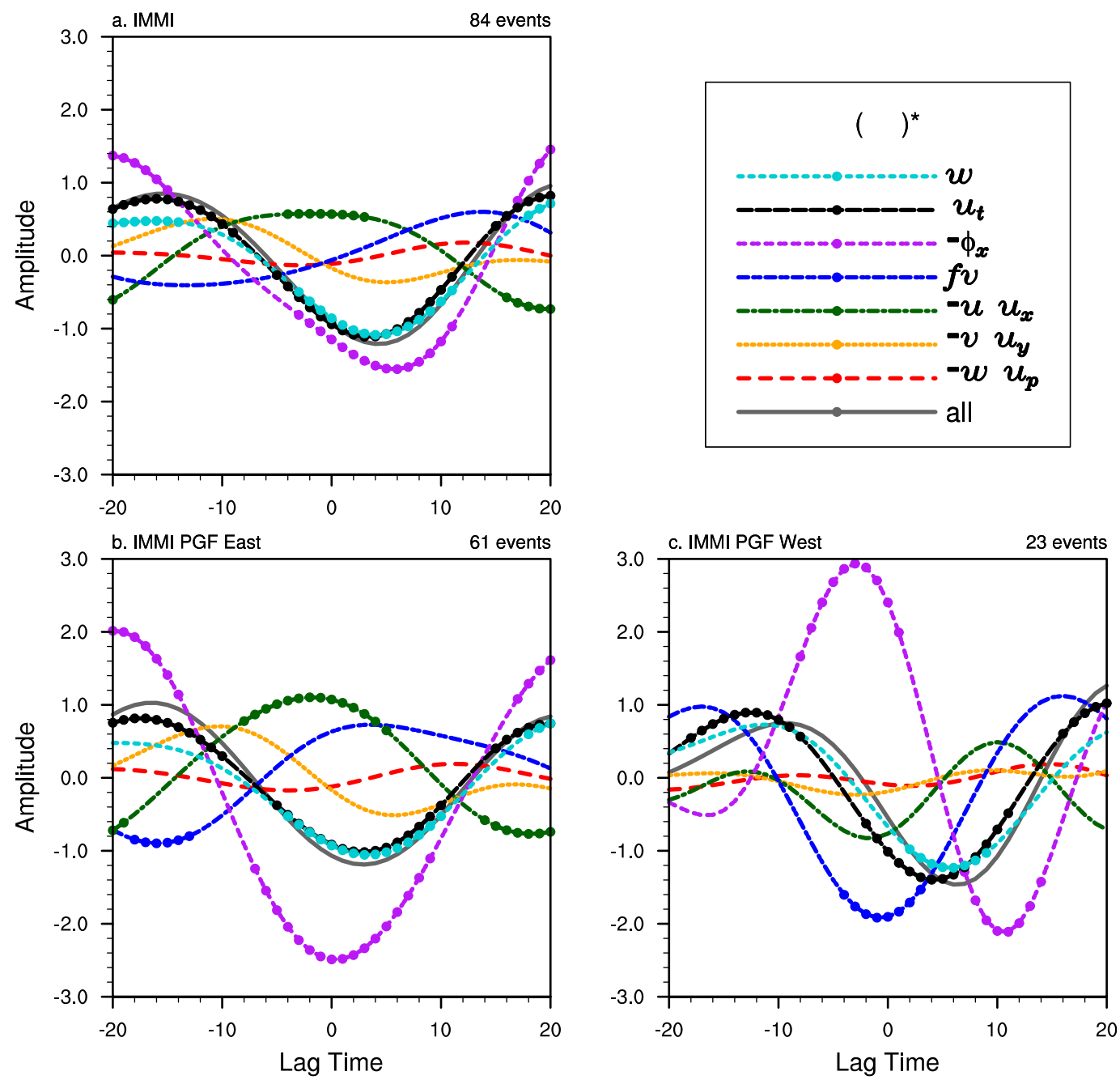

FIG. 9. Intraseasonal zonal momentum budget terms at $200 \mathrm{hPa}\left(\times 10^{-5} \mathrm{~m} \mathrm{~s}^{-2}\right)$ and intraseasonal vertical velocity at $500 \mathrm{hPa}$ (turquoise; $\times 100 \mathrm{hPa} \mathrm{s}^{-1}$ ) averaged over $10^{\circ} \mathrm{S}-10^{\circ} \mathrm{N}, 50^{\circ}-60^{\circ} \mathrm{E}$ for (a) IMMI, (b) IMMI PGF easterly, and (c) IMMI PGF westerly events. Markers represent where values are significant. "All” represents the sum of all budget terms other than the tendency term.

acceleration signals that reach the western Indian Ocean around lag zero for IMMI (Fig. 7b). While the overall easterly acceleration signals circumnavigate, a discontinuity exists in the strength of the signal, such that there is a local minimum in the time tendency over the western Indian Ocean. The anomaly moves faster over the Western Hemisphere and slows down as it reaches the warm pool region. Additionally, the circumnavigating negative time tendency of momentum is in phase with both midtropospheric $(500 \mathrm{hPa})$ upward vertical motion (Fig. 7b) and upper-level divergence (not shown), suggesting that the acceleration of easterly winds could help provide a dynamical reduction in subsidence that may trigger MJO convective initiation (Powell and Houze $2013,2015)$ as easterly acceleration intrudes upon the west side of a region that previously had westerly wind anomalies. At lag zero, the acceleration of easterly winds is maximized over the western Indian Ocean (Fig. 7a). While the easterly acceleration is at its largest amplitude over the western Indian Ocean, it extends from $150^{\circ} \mathrm{W}$ to $90^{\circ} \mathrm{E}$ over the tropics at this time with a pair of secondary maxima over the Atlantic near $10^{\circ} \mathrm{N}$ and $10^{\circ} \mathrm{S}$. Westerly acceleration is present over the subtropics proximate to Africa.

Since the easterly tendency is maximized near $10^{\circ} \mathrm{S}-$ $10^{\circ} \mathrm{N}, 50^{\circ}-60^{\circ} \mathrm{E}$ at lag zero (Fig. 7a), and this region has the largest intraseasonal variance of zonal wind along the equator in the Eastern Hemisphere (Fig. 1b), we analyze this area further. Almost all (76 out of 84 events) have easterly intraseasonal time tendency averaged over this box at lag zero. For the events that have westerly time tendency, negative intraseasonal OLR signals form 
later over the tropical western Indian Ocean (Fig. 8), such that the classification of westerly time tendency likely only results from the timing of IMMI relative to the onset of convection over the eastern Indian Ocean. The maintenance of the in-phase relationship of the easterly acceleration and negative OLR for both sets of events supports the hypothesis that the easterly tendency provides large-scale dynamical forcing conducive to MJO convective onset, though the number of westerly tendency events is not large enough to have confidence in significance testing because the sample might not be sufficiently representative.

We evaluate the temporal evolution of all of the intraseasonal zonal momentum budget terms averaged over $10^{\circ} \mathrm{S}-10^{\circ} \mathrm{N}, 50^{\circ}-60^{\circ} \mathrm{E}$, near where the easterly acceleration is maximized at lag zero (Fig. 7a). Though negative at lag zero, the minimum in zonal tendency in the box does not occur until a lag of 3 days (black line; Fig. 9a). The zonal tendency is essentially in phase with the $500-\mathrm{hPa}$ intraseasonal vertical velocity (turquoise), which reaches its maximum in upward motion at a lag of 4 days within the box. Within the chosen box, the pressure gradient force (PGF; purple) has the largest magnitude of any term and is mainly in phase with the time tendency, with the minimum PGF occurring at a lag of 6 days (Fig. 9a). Meridional advection (orange) is at its minimum 5 days after lag zero, though with an amplitude of about one-third of the tendency. Two terms lead the tendency: though small, the vertical advection (red) minimum occurs 3 days before lag zero and the Coriolis force (blue) leads the tendency by 13 days, switching from negative to positive around lag zero. To balance out the easterly acceleration, the zonal advection (green) is strong westerly around convective onset, peaking 2 days before lag zero. All of the aforementioned terms approximately add up to the time tendency, indicating that the residual is relatively small. Of the budget terms, only the tendency, PGF, and zonal advection are statistically significant at the $95 \%$ level around lag zero when averaged within the box, though other terms have significance when viewed spatially and when cases are further subdivided, indicating that their contributions should not be neglected. Overall, the PGF term provides the most easterly acceleration within the box in the composite, such that we sort and analyze events based on this term in section $3 \mathrm{~d}$.

\section{d. Separation of events with easterly and westerly $P G F$}

To better understand the processes leading to easterly tendency in the box, we separate events into two groups: those where the intraseasonal PGF imposes easterly acceleration and those where the intraseasonal PGF imposes westerly acceleration over $10^{\circ} \mathrm{S}-10^{\circ} \mathrm{N}, 50^{\circ}-60^{\circ} \mathrm{E}$
TABLE 1. List of events that have been selected by IMMI and subdivided into PGF easterly and PGF westerly categories.

\begin{tabular}{|c|c|c|c|}
\hline & \multicolumn{2}{|c|}{ PGF easterly } & PGF westerly \\
\hline Number of events & \multicolumn{2}{|c|}{61} & 23 \\
\hline \multirow[t]{31}{*}{ List of events } & $20 \operatorname{Dec} 1979$ & 11 Jan 1998 & 3 Apr 1980 \\
\hline & 24 Feb 1980 & 25 Mar 1998 & 18 Mar 1981 \\
\hline & 6 Nov 1980 & 7 Mar 1999 & 7 Dec 1983 \\
\hline & 20 Dec 1980 & 20 Nov 1999 & 27 Mar 1984 \\
\hline & 30 Apr 1981 & 17 Feb 2000 & 23 Mar 1985 \\
\hline & 11 Apr 1982 & 10 Nov 2000 & 29 Nov 1986 \\
\hline & 31 Jan 1983 & 9 Jan 2002 & 6 Mar 1988 \\
\hline & 21 Jan 1984 & 7 Mar 2002 & 23 Mar 1989 \\
\hline & 6 Nov 1984 & 19 Apr 2002 & 11 Feb 1990 \\
\hline & 27 Jan 1985 & 1 Nov 2002 & 13 Dec 1991 \\
\hline & 5 Mar 1986 & 15 Dec 2002 & 6 Jan 1993 \\
\hline & 19 Apr 1986 & 29 Jan 2003 & 4 Jan 1994 \\
\hline & 9 Jan 1988 & 19 Apr 2003 & 22 Apr 1995 \\
\hline & 19 Apr 1988 & 3 Nov 2003 & 16 Mar 1996 \\
\hline & 2 Jan 1989 & 17 Jan 2004 & 30 Apr 1998 \\
\hline & 11 Feb 1989 & 25 Feb 2004 & 7 Jan 1999 \\
\hline & 16 Dec 1989 & 22 Jan 2005 & 18 Mar 2003 \\
\hline & 29 Mar 1990 & 22 Nov 2005 & 11 Apr 2004 \\
\hline & 30 Nov 1990 & 18 Feb 2006 & 14 Mar 2005 \\
\hline & 5 Jan 1991 & 17 Dec 2006 & 25 Apr 2005 \\
\hline & 30 Jan 1992 & 9 Apr 2007 & 1 Jan 2006 \\
\hline & 22 Mar 1992 & 3 Dec 2007 & 10 Apr 2008 \\
\hline & 16 Feb 1993 & 22 Jan 2008 & 20 Jan 2009 \\
\hline & 27 Nov 1993 & 9 Mar 2008 & \\
\hline & 2 Feb 1994 & 30 Mar 2009 & \\
\hline & 25 Dec 1994 & 12 Dec 2009 & \\
\hline & 15 Dec 1995 & 26 Apr 2010 & \\
\hline & 18 Nov 1996 & 11 Mar 2011 & \\
\hline & 26 Jan 1997 & 12 Jan 2012 & \\
\hline & 21 Mar 1997 & 21 Feb 2012 & \\
\hline & 25 Apr 1997 & & \\
\hline
\end{tabular}

at lag zero, because the PGF is the dominant term in the composite (Fig. 9a). The separation of events combines similar cases with one another, as all events do not evolve in the same manner. The pressure gradient force over the box is easterly for 61 out of 84 events, more than for any term other than the time tendency. Identified events and their specific breakdown into categories are shown in Table 1. All three of the cases analyzed in the modeling study of Ray et al. (2011) are identified here as PGF easterly. Additionally, the events during the main observation period of DYNAMO (during fall and winter 2011) were not selected by the IMMI index, likely because of the shorter time scale of these events (not shown); however, the events that begin in January and February 2012 at the tail end of the campaign are identified as PGF easterly.

The general consistency of horizontal structures for both the intraseasonal zonal momentum tendency and OLR (Fig. 10) between PGF easterly and PGF westerly events suggests that the primary difference between the separated events resides in the contributions from 

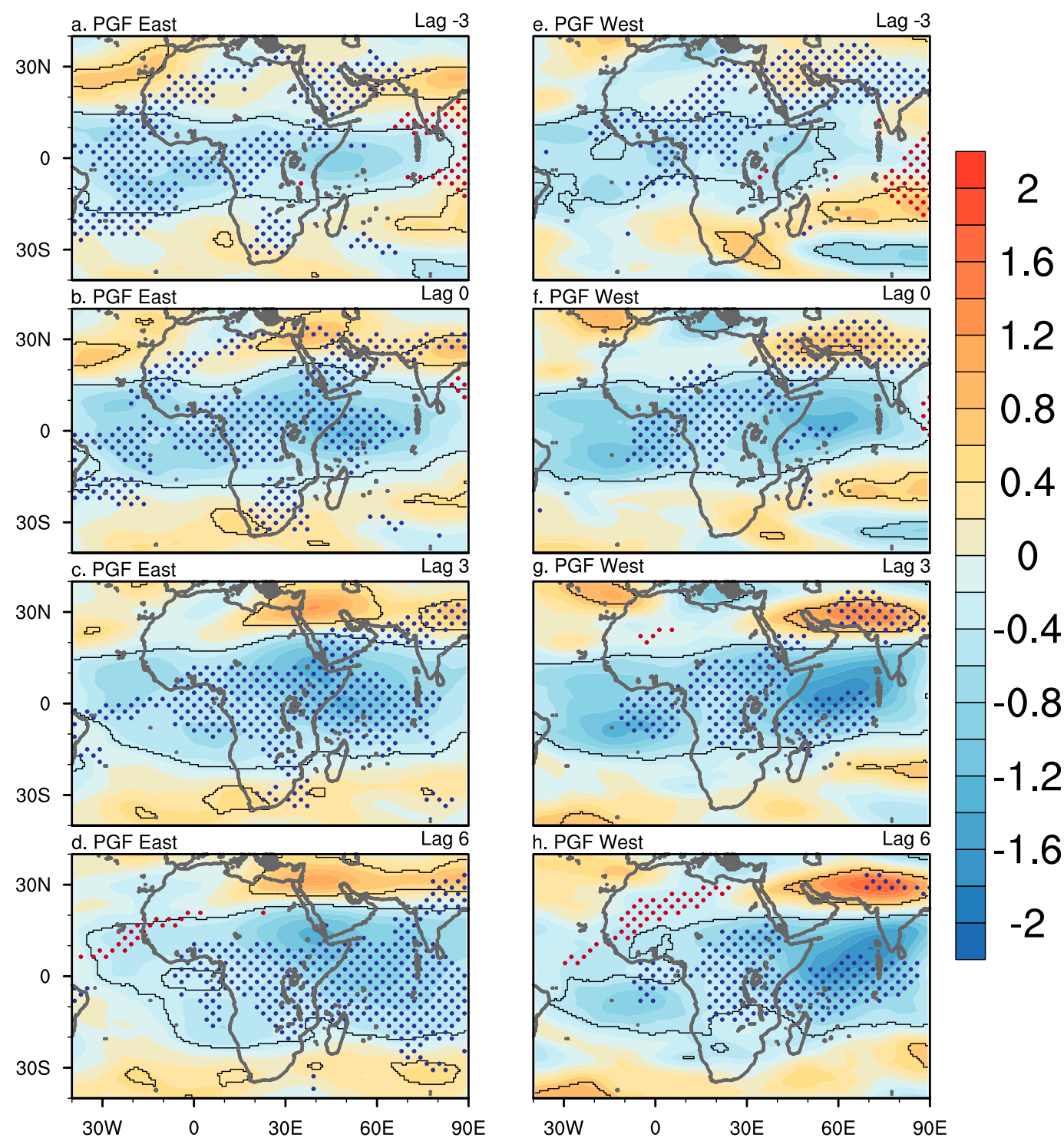

FIG. 10. Intraseasonal zonal momentum tendency at $200 \mathrm{hPa}\left(10^{-5} \mathrm{~m} \mathrm{~s}^{-2}\right.$; shaded) and intraseasonal OLR (dots) for events where the PGF is (a)-(d) easterly and (e)-(h) westerly at lag zero over $10^{\circ} \mathrm{S}-10^{\circ} \mathrm{N}, 50^{\circ}-60^{\circ} \mathrm{E}$ at lags of (top to bottom) $-3,0,3$, and 6 days. Contours show where tendency is locally significant at the $95 \%$ level, and dots are only where OLR is significant.

different budget terms, as opposed to differences in convection for the resulting events.

\section{1) BUdGET TERMS}

For the PGF easterly events, timings of terms are mainly in agreement with the zonal momentum budget for the full set of events (Figs. 9a,b), though easterly acceleration from the PGF leads both the tendency term and the vertical velocity by 3 days (Fig. $9 b$ ). This phasing is in contrast with the zonal momentum budget for MJO deep convection over the warm pool (Lin et al. 2005), where the local zonal acceleration leads the PGF by one-fourth of a cycle. Instead, the phasing suggests an in-phase relationship between the zonal wind and geopotential height, consistent with a theoretical Kelvin wave. However, the horizontal structure of the PGF term does not suggest propagation from the west as would be expected if the term were initially forced by Kelvin wave dynamics (Figs. 11a-d, 12a). Over the Western Hemisphere and Africa, PGF signals are out of phase with the time tendency and reverse in sign at a wavenumber 6 zonal scale in a pattern connected to the extratropics (Figs. $11 \mathrm{a}-\mathrm{d}, 12$ ). Near $50^{\circ}-60^{\circ} \mathrm{E}$, easterly acceleration due to the pressure gradient force moves equatorward 

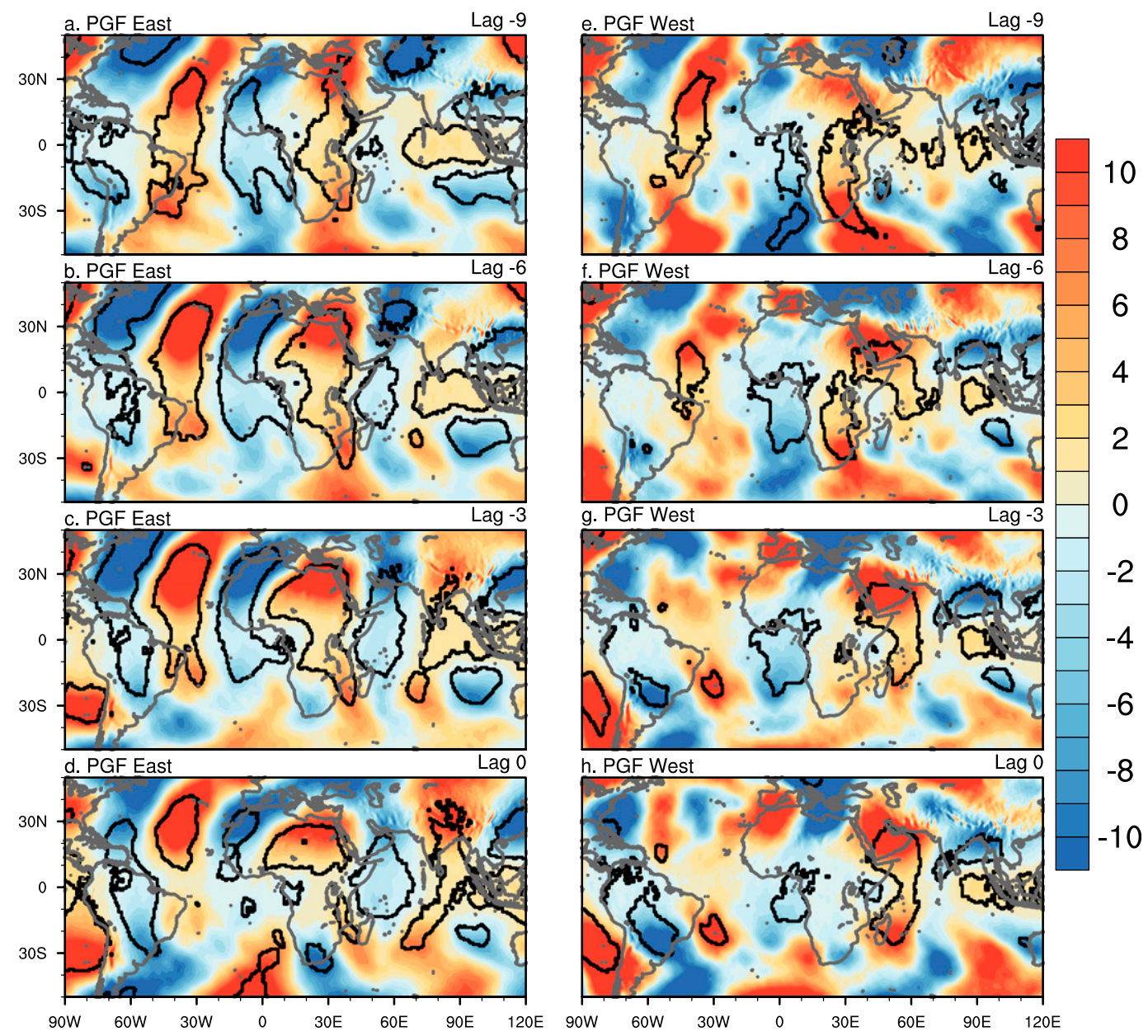

FIG. 11. Intraseasonal PGF at $200 \mathrm{hPa}\left(10^{-5} \mathrm{~m} \mathrm{~s}^{-2}\right)$ for events in which the PGF is (a)-(d) easterly and (e)-(h) westerly at lag zero over $10^{\circ} \mathrm{S}-10^{\circ} \mathrm{N}, 50^{\circ}-60^{\circ} \mathrm{E}$ at lags of (top to bottom) $-9,-6,-3$, and 0 days. Contours show where results are significant at the $95 \%$ level.

from the extratropics at a phase speed around $5 \mathrm{~m} \mathrm{~s}^{-1}$ leading up to lag zero (Figs. 11a-d, 12b). The Northern Hemisphere signal is stronger than the Southern Hemisphere signal, though the Southern Hemisphere intrusion appears sooner, with signals reaching the tropics around lags of -2 and -4 days, respectively. While weaker, the Southern Hemisphere signal may be just as (or more) crucial as the Northern Hemisphere signal since it is better able to reach a region of warmer SSTs that has higher convective potential. Local forcing may also contribute to the easterly acceleration from the PGF over the tropics. Only in the days after lag zero, as convection deepens, does the easterly PGF anomaly expand zonally then propagate eastward, lagging the overall tendency by one-fourth of a cycle over the warm pool (Figs. 7b, 12a).

While the horizontal structure of the PGF suggests that the zonal acceleration in this region is not caused by a disturbance circumnavigating the tropics, it is possible that circumnavigating upward motion reaching the western Indian Ocean and local convection could cause convective heating, thus forcing the PGF. Although we cannot entirely eliminate this alternate hypothesis without modeling, we argue for influence from the extratropics for the following reasons [as well as the dynamical support shown in sections $3 d(2)-(4)]$. First, the intraseasonal PGF leads both the time tendency and vertical velocity by 3 days for the PGF easterly events (Fig. 9b). Additionally, the similarity in locations of OLR (dots; Fig. 10) for easterly and westerly PGF events, along with similar circumnavigating signals in the zonal wind tendency, yet the one-fourth of a cycle lag between the vertical velocity and the PGF in the PGF westerly cases (Fig. 9c) suggests that the circumnavigating and convective signals may not be responsible for the in-phase easterly PGF. Moreover, we are able to find a few PGF easterly events that do not have intraseasonal easterly acceleration 

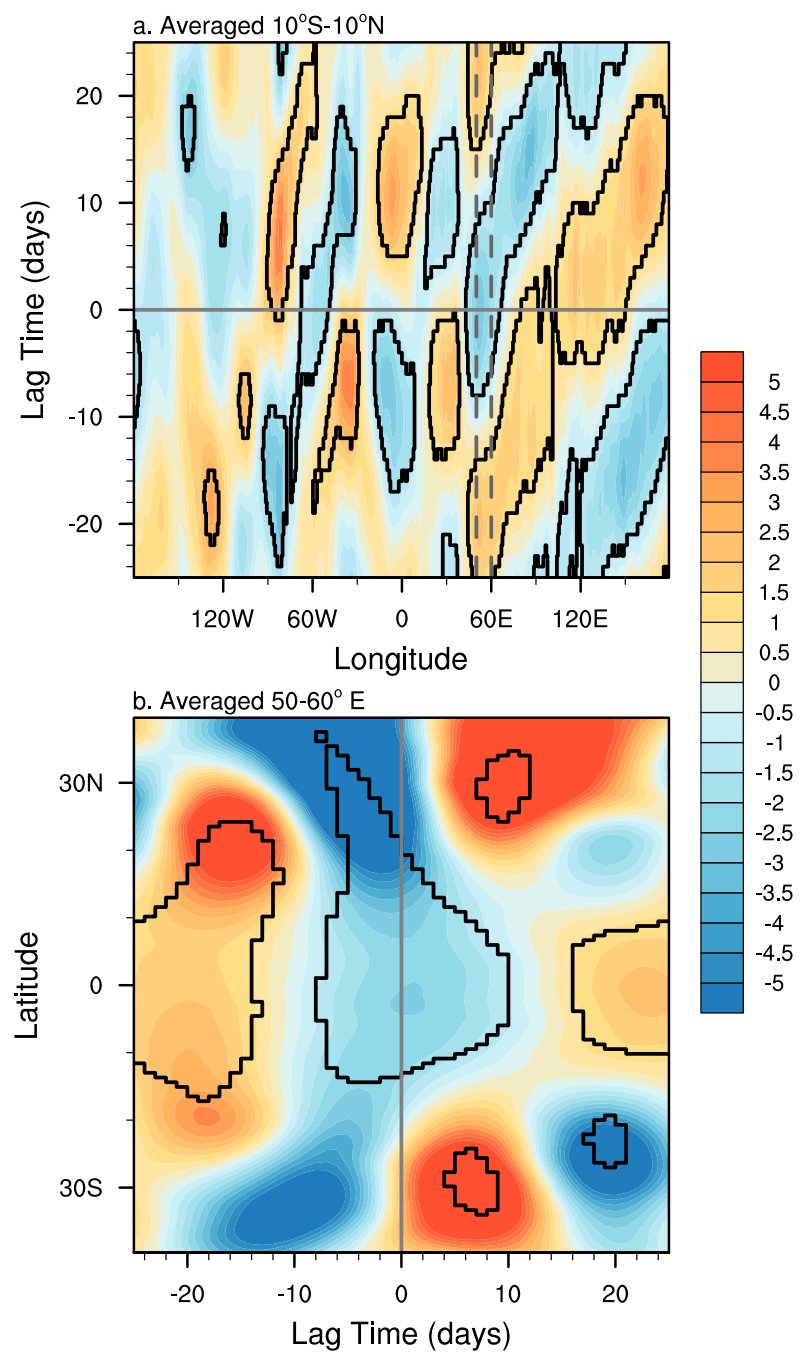

FIG. 12. (a) Lag time vs longitude and (b) latitude vs lag time diagrams of the intraseasonal PGF $\left(10^{-5} \mathrm{~m} \mathrm{~s}^{-2}\right)$ at $200 \mathrm{hPa}$ averaged over $10^{\circ} \mathrm{S}-10^{\circ} \mathrm{N}$ and (b) $50^{\circ}-60^{\circ} \mathrm{E}$ for IMMI easterly PGF composites. Contours show significance at the $95 \%$ level. Solid lines show lag zero, and dashed lines show area in the latitude vs lag time diagram.

across Africa at lag zero as well as events that do not have negative (intraseasonal) OLR over the western Indian Ocean at lag zero (not shown). Furthermore, the circumnavigating tropical upward motion may not fully be independent of the extratropics, as intrusions of extratropical wave trains help to force updrafts near South America leading up to MJO convective onset (Sakaeda and Roundy 2016). While these findings do not eliminate the possibility of influence from the circumnavigating signals and the local convection on the PGF in some events, these results suggest that these factors are not necessary for forming the initial pressure gradient around the time of convective onset, such that the extratropics may play a role.
For the small subset of westerly PGF cases, easterly acceleration results from a combination of Coriolis, vertical advection, and meridional advection (Fig. 9c), in the absence of easterly acceleration from the PGF and strong westerly zonal advection (the major players for easterly PGF cases).

\section{2) Dynamical EVOLUTiON}

For the easterly PGF events, zonally extended positive 200-hPa geopotential height anomalies set up over the tropics near the western Indian Ocean around 15 days before lag zero (Fig. 13a); zonally extended negative anomalies over the subtropics begin to form about 12 days before lag zero (Fig. 13b). The negative subtropical geopotential height anomalies are consistent with the negative OLR precursors over the subtropics (Fig. 6), and may be (at least partially) a response to MJO suppressed convection over the tropics of the Indian Ocean (e.g., Barlow et al. 2007). On the poleward sides of the subtropical gyres are extratropical Rossby wave trains that extend back across the Atlantic Ocean, with negative geopotential height anomalies positioned within $30^{\circ}-50^{\circ} \mathrm{S}, 30^{\circ}-50^{\circ} \mathrm{E}$ and $30^{\circ}-50^{\circ} \mathrm{N}, 30^{\circ}-50^{\circ} \mathrm{E}$ at 12 days before lag zero (Fig. 13b). Six days before through lag zero, the corresponding 200-hPa intraseasonal streamfunction indicates equatorward motion over eastern Africa (Figs. 14d-f). This flow allows the wave trains and negative geopotential height anomalies to move equatorward along the gyres' western edges. In the tropics along the east coast of Africa (around $35^{\circ}-45^{\circ} \mathrm{E}$ ), the geopotential height begins to decrease 6 days before lag zero and turns negative by lag zero. The weakening of the positive geopotential height anomalies is sufficient to form a positive gradient in geopotential height over the western Indian Ocean. As the negative anomalies intrude over eastern Africa, the tropical positive geopotential height anomalies extend eastward over the Indian Ocean but remain over western Africa. While MJO deep convection builds over the western Indian Ocean, the subtropical uppertropospheric cyclones are replaced by subtropical anticyclones, which allow for convective outflow, coupling to the convection and projecting a new wave pattern in the extratropics. Negative geopotential height anomalies also encroach into the tropics over the Atlantic Ocean slightly before and concurrent with the intruding anomaly over eastern Africa, associated with the overall flow pattern and extratropical wave train that develops leading up to MJO convective onset.

We confirm that at least initially the negative geopotential height anomalies do not circumnavigate from the west but instead originate near the east coast of Africa, as shown by a time-longitude diagram (Fig. 15a). 

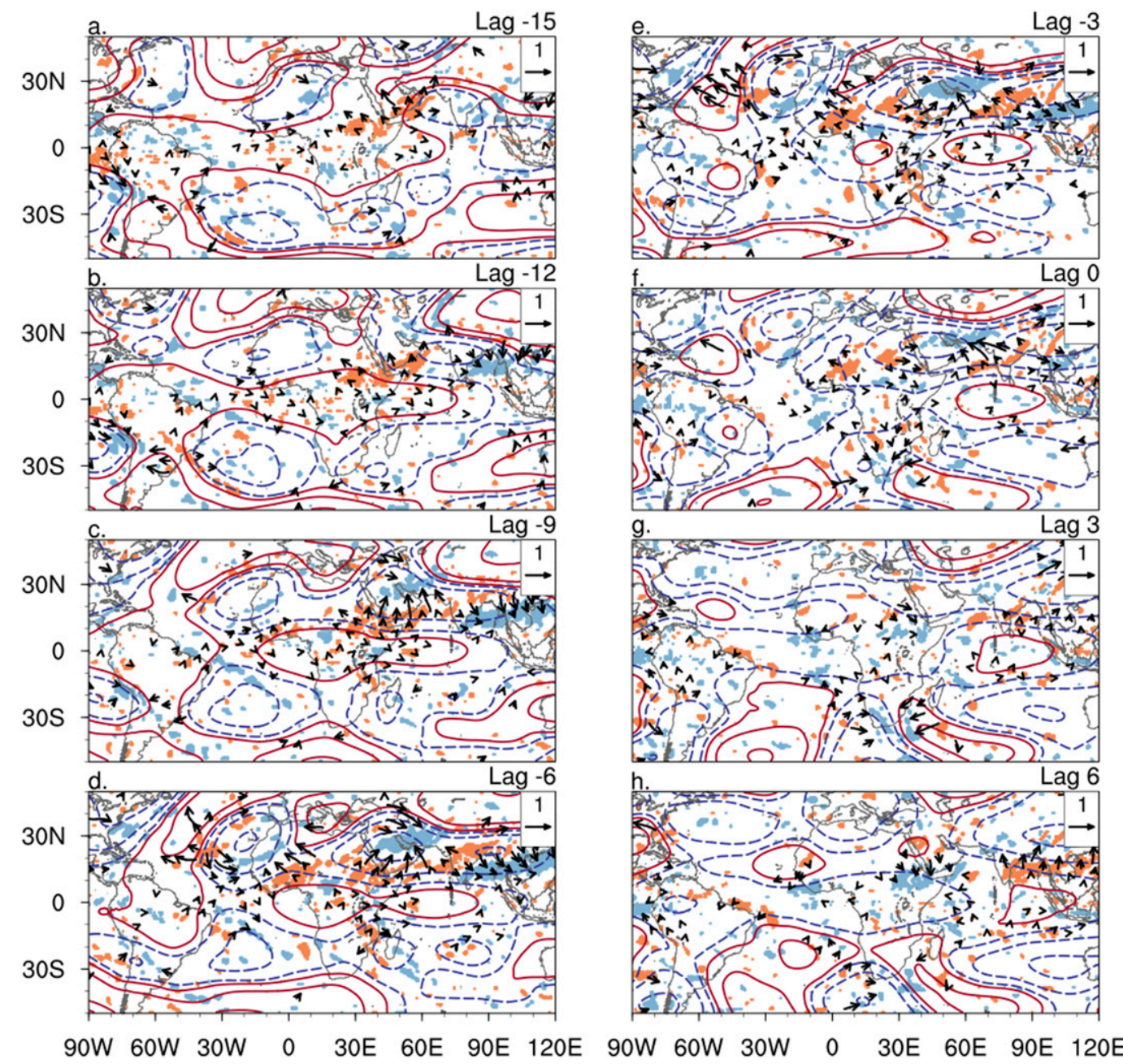

FIG. 13. Intraseasonally filtered 200-hPa geopotential height anomalies (m; contours at $-24,-12,-3,3,12$, $24 \mathrm{~m})$, intraseasonal $\mathrm{Q}$ vectors averaged from 400 to $200 \mathrm{hPa}\left(\times 10^{-13} \mathrm{~m}^{2} \mathrm{~s}^{-1} \mathrm{~kg}^{-1}\right.$; vectors), and Q-vector convergence (blue) and divergence (red) for events where the PGF is easterly at lag zero over $10^{\circ} \mathrm{S}-10^{\circ} \mathrm{N}, 50^{\circ}-60^{\circ} \mathrm{E}$ at lags of (a) -15 , (b) -12 , (c) -9 , (d) -6 , (e) -3 , (f) 0 , (g) 3, and (h) 6 days. Vectors and shading are only plotted where results are significant at the $95 \%$ level. Significance of the geopotential height is shown later in Fig. 15.

The strong geopotential height anomaly over western Africa forms later, with evidence of eastward movement from the Atlantic. The three centers of negative geopotential height anomalies over the Western Hemisphere do not appear to be part of a continuous eastwardpropagating disturbance but instead are separated in the tropics, with small temporal delays of about 4 days between the anomalies over the east Pacific and Africa. Only after the negative geopotential height anomaly forms over eastern Africa does the signal over the Atlantic move eastward. On the other hand, the meridional continuity of the $200-\mathrm{hPa}$ intraseasonal geopotential height is confirmed via a latitude-lag diagram that is averaged between $35^{\circ}$ and $45^{\circ} \mathrm{E}$, just to the west of the region with the negative PGF (Fig. 15b).
The geopotential height anomalies do weaken near $15^{\circ}-20^{\circ} \mathrm{S}$ and $15^{\circ}-20^{\circ} \mathrm{N}$; however, this is likely due to the decline of extratropical Rossby waves as they approach the equator with subsequent strengthening after lag zero as convection grows and the circumnavigating tropical circulation signal approaches.

\section{3) VerticAl STRUCTURE}

To further understand the process by which the pressure gradient forces easterly acceleration leading up to MJO onset, we ascertain the evolution of verticalmeridional structures of the intraseasonal geopotential height as well as intraseasonal meridional and vertical velocity averaged between $35^{\circ}$ and $45^{\circ} \mathrm{E}$, just to the west of the region with easterly PGF. Nine days before lag 

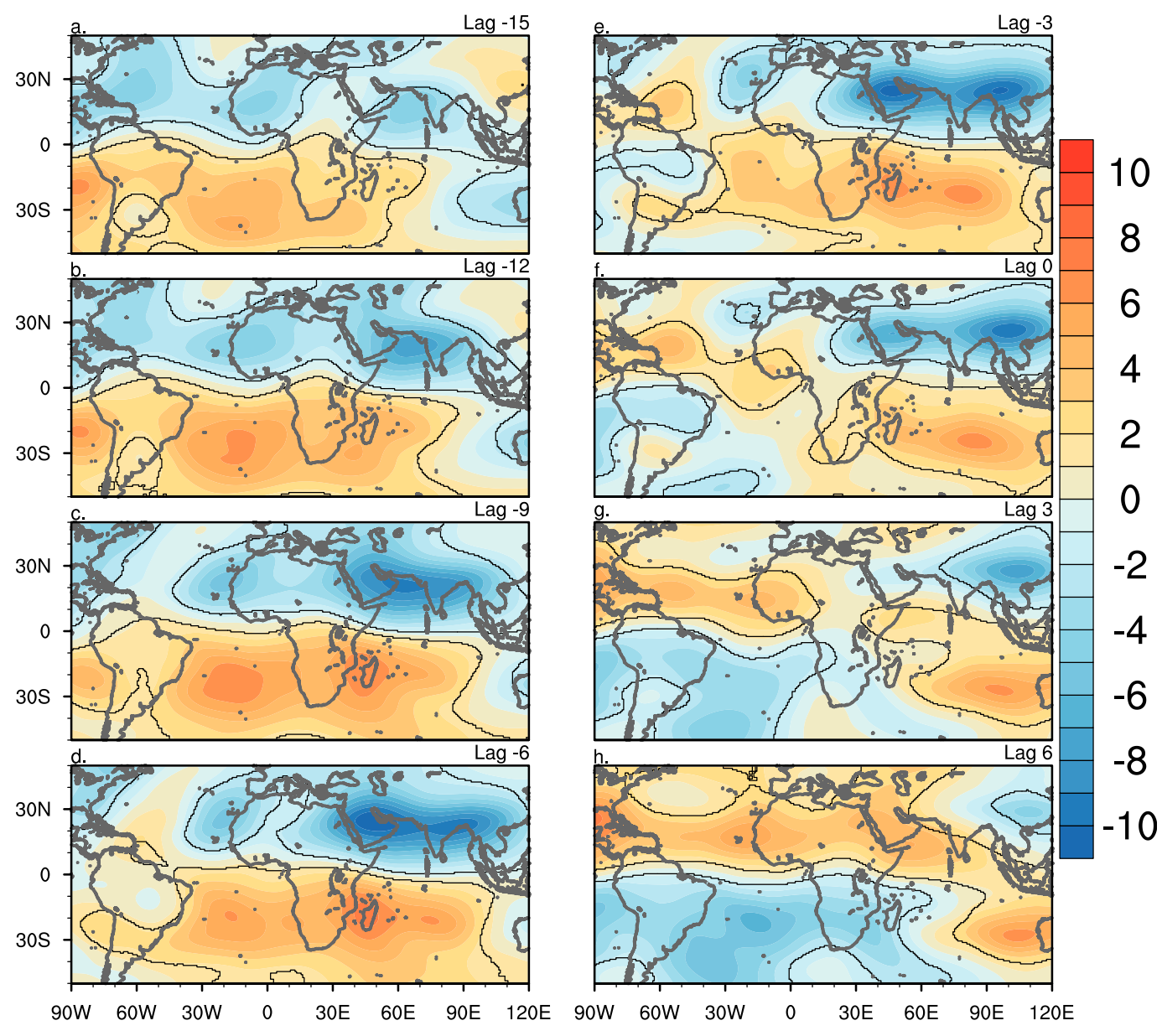

FIG. 14. Intraseasonally filtered 200-hPa streamfunction $\left(\times 10^{6} \mathrm{~m}^{2} \mathrm{~s}^{-1}\right)$ for events where the PGF is easterly at lag zero over $10^{\circ} \mathrm{S}-10^{\circ} \mathrm{N}, 50^{\circ}-60^{\circ} \mathrm{E}$ at lags of (a) -15 , (b) -12 , (c) -9 , (d) -6 , (e) -3 , (f) 0 , (g) 3, and (h) 6 days. Contours show where results are significant at the $95 \%$ level.

zero for the easterly PGF events (Fig. 16a), uppertropospheric geopotential height anomalies are located over the subtropics in both the Northern and Southern Hemispheres. The corresponding upper-tropospheric meridional flow is equatorward and vertical motion is upward in the region of the negative geopotential height anomalies. Stepping forward in time, the negative geopotential height anomalies reach downward and equatorward coherent with lower-tropospheric upward motion (Figs. 16b,c). By lag zero (Fig. 16d), upward vertical motion in the lower and midtroposphere has approached the equator along with statistically significant lower- and midtropospheric negative geopotential height anomalies that extend to both hemispheres. Statistically significant negative geopotential height anomalies and upward vertical motion expand to the upper troposphere by 3 days after lag zero (Fig. 16e). The subtropical negative geopotential height anomalies weaken as signals move equatorward; the Southern Hemisphere negative geopotential height anomaly disappears by 3 days after lag zero (Fig. 16e) and the Northern Hemisphere signal by 6 days after lag zero (Fig. 16f). Overall, negative upper-tropospheric geopotential height anomalies along the east coast of Africa are associated with upward vertical motion moving equatorward from the extratropics. Similar intrusions of negative geopotential height caused by updrafts are found near South America associated with the MJO precursor signal circumnavigating in the extratropics but then intruding on the tropics of the Western Hemisphere (Sakaeda and Roundy 2016).

\section{4) Q Vectors}

Further evidence of the extratropical origin of the system and its upward vertical motion is diagnosed through the use of Q-vector dynamics. Intraseasonal Q vectors averaged from 400 to $200 \mathrm{hPa}$ mainly point toward the regions of strong negative geopotential height anomalies in the subtropics (around $30^{\circ} \mathrm{N}, 35^{\circ}-70^{\circ} \mathrm{E}$ or 

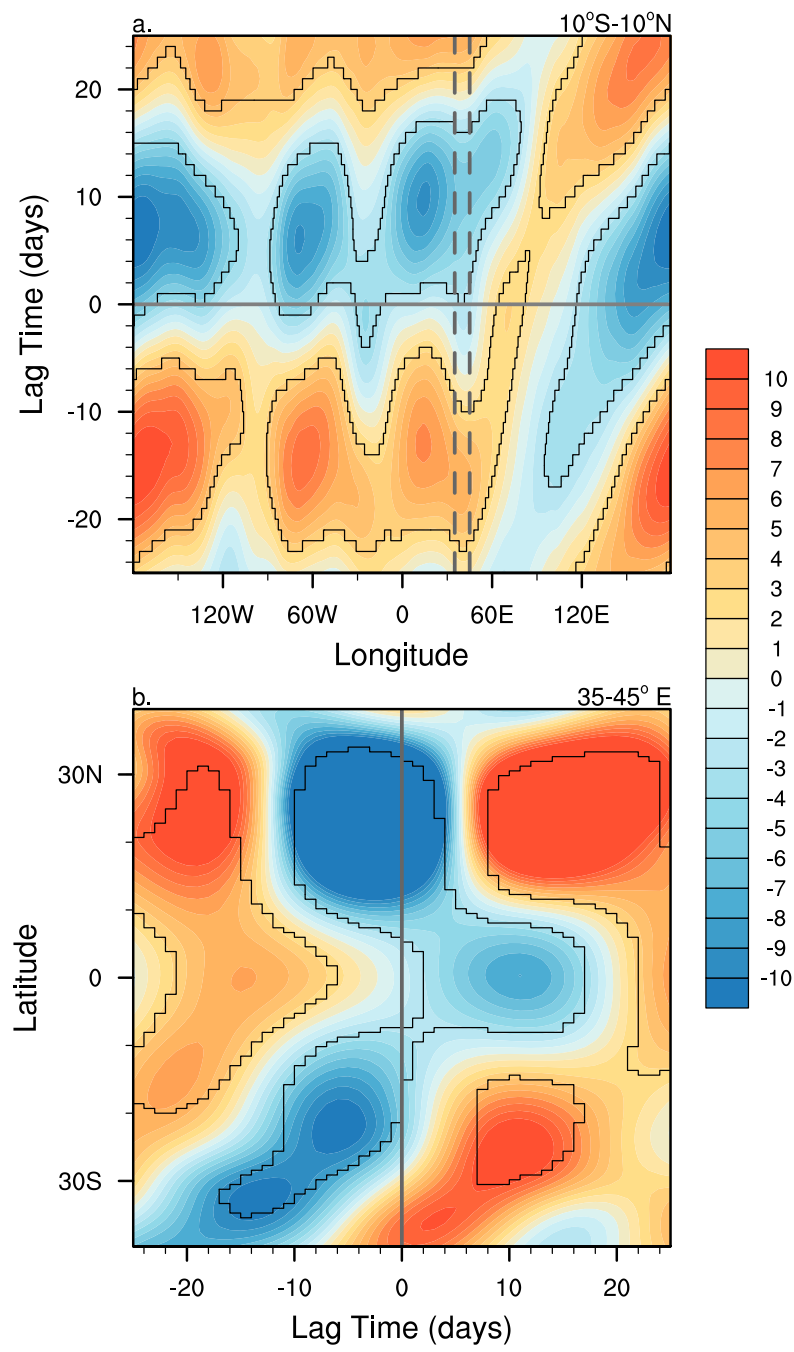

FIG. 15. (a) Lag time vs longitude and (b) latitude vs lag time diagrams of the intraseasonal geopotential height $(\mathrm{m})$ at $200 \mathrm{hPa}$ averaged over (a) $10^{\circ} \mathrm{S}-10^{\circ} \mathrm{N}$ and (b) $35^{\circ}-45^{\circ} \mathrm{E}$ for IMMI easterly PGF composites. Contours show significance at the $95 \%$ level. Solid lines show lag zero, and dashed lines show area in the latitude vs lag time diagram.

$\left.30^{\circ} \mathrm{S}, 35^{\circ}-70^{\circ} \mathrm{E}\right)$ in the days leading up to MJO onset with corresponding Q-vector convergence (Figs. 13b-e), corroborating that the negative geopotential height anomalies are associated with a dynamically forced upward motion. During the same time period, Q-vector divergence (or downward forcing) is present on the equatorward sides of the Q-vector convergence (between $20^{\circ} \mathrm{S}$ and $20^{\circ} \mathrm{N}$ ). By lag zero (Fig. 13f), the Q-vector divergence diminishes and the Q-vector convergence subsequently progresses southward (though noisily) consistent with the negative geopotential height. Between $35^{\circ}$ and $45^{\circ} \mathrm{E}$ at lags -9 through -3 days, the locations of strongest Q-vector convergence in the Northern Hemisphere align with the regions of upward vertical motion shown in the vertical cross sections
(Figs. 13c-e, 16a-c) before the upward vertical motion expands to the equator. While the dynamical Q-vector convergence may not reach the equator, the initial coupling between the negative geopotential height anomalies and Q-vector convergence supports the premise that the pressure gradient has an extratropically forced element that acts on intraseasonal time scales.

\section{Discussion}

Leading up to MJO convective onset, intraseasonal easterly acceleration of zonal momentum in the upper troposphere creates a flow pattern of upper-tropospheric divergence when arriving over the western Indian Ocean on the west side of a region of intraseasonal westerly anomalies. The upper-tropospheric divergence may then help form the in-phase large-scale reduction in subsidence. Observations from DYNAMO (Powell and Houze 2013, 2015) suggest that large-scale reductions in subsidence at $300 \mathrm{hPa}$ steepen the lapse rate in the lower troposphere, allowing cumulus congestus to grow vertically and moisten the upper troposphere, triggering MJO deep convection. Literature for convection in general agrees that favorable large-scale dynamics may be fundamental for the initial organization and amplification of deep convection (Hohenegger and Stevens 2012). Nonetheless, while the easterly tendency corresponds to midlevel upward vertical velocity, certain thermodynamic constraints may also be necessary for subsequent MJO convection onset, such that all occurrences of intraseasonal easterly acceleration over the region may not lead to active MJO convection.

By analysis of the intraseasonal zonal momentum budget over the western Indian Ocean using the regional index and further isolation of the dominant group of events, we identify a mechanism whereby the extratropics may influence the tropics leading up to MJO convective onset. The characteristics of the terms contributing to the circumnavigating easterly tendency near eastern Africa and the western Indian Ocean are distinct from zonal momentum budget signals for active convection over the warm pool, where the PGF lags the tendency by one-fourth of a cycle (Lin et al. 2005), as well as those over the east Pacific Ocean (Sakaeda and Roundy 2015). For about three-quarters of the identified events, the in-phase pressure gradient force accelerates easterlies over the tropical western Indian Ocean at lag zero. The easterly PGF does not initially propagate from the west and leads the upward vertical velocity by a few days, suggesting that circumnavigating Kelvintype wave dynamics may not form over the region until after convective onset. Rather, in the composite, the pressure gradient is caused by extratropical negative 

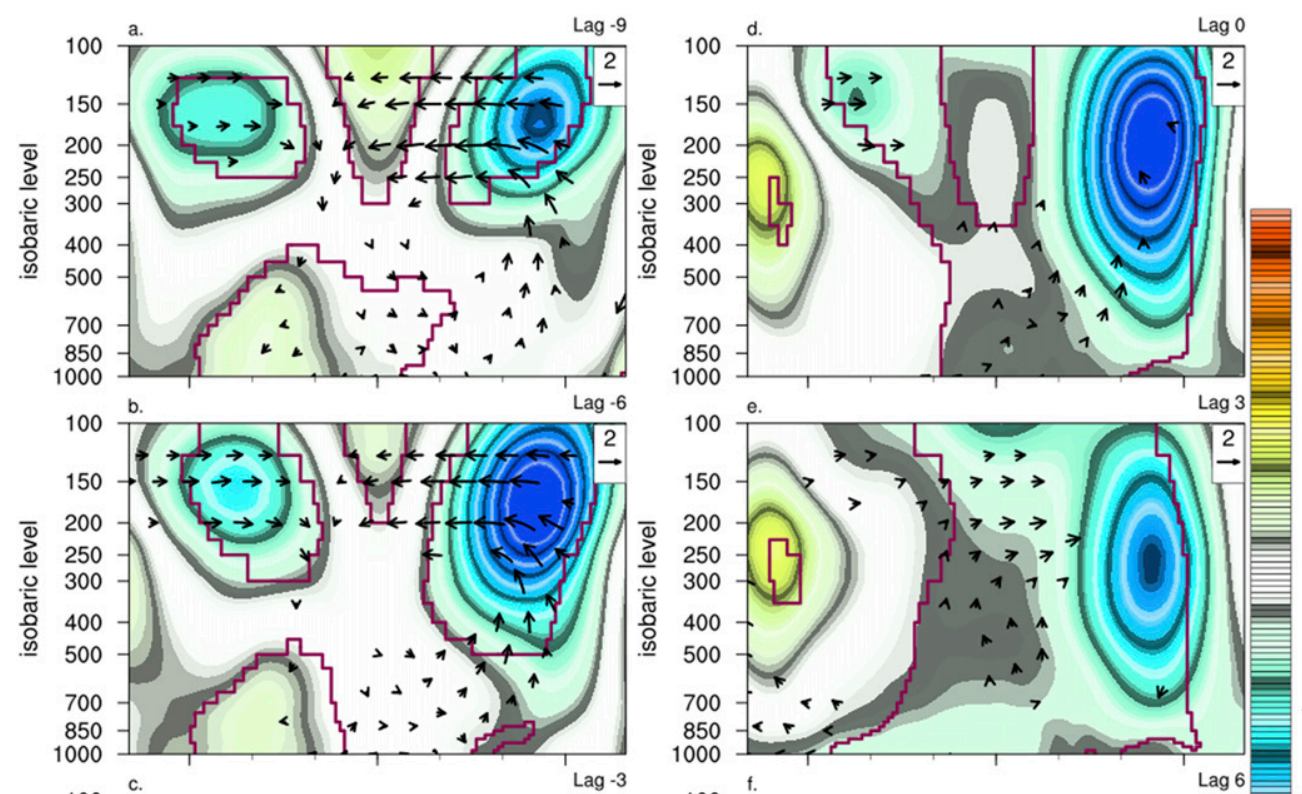

\section{1}

17.5

14

10.5
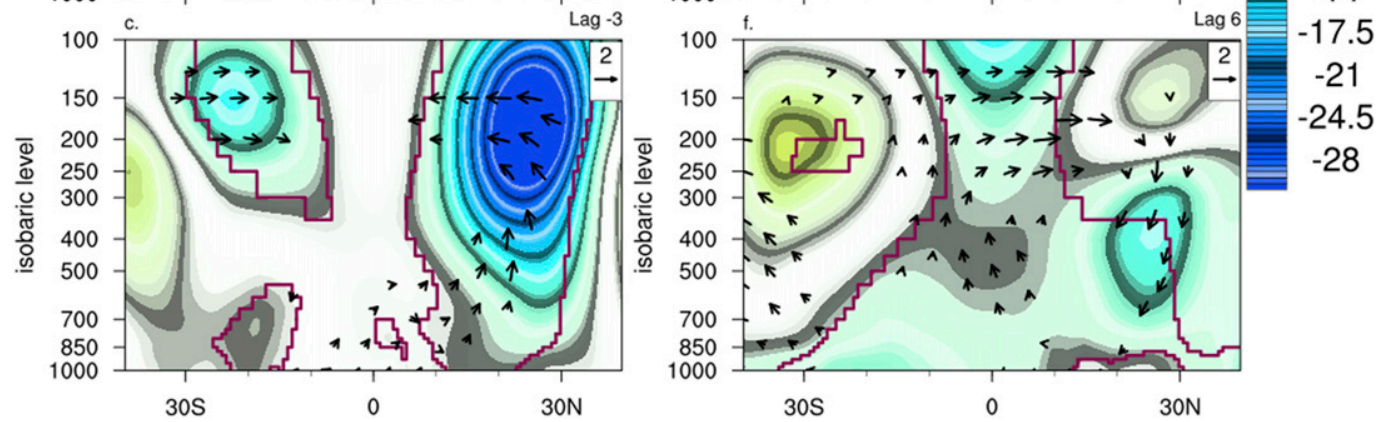

FIG. 16. Vertical-meridional cross section of intraseasonal geopotential height ( $\mathrm{m}$; shading) with meridional and vertical winds ( $\mathrm{m} \mathrm{s}^{-1}$ and $\times 100 \mathrm{hPa} \mathrm{s}^{-1}$, respectively; vectors) averaged over $35^{\circ}-45^{\circ} \mathrm{E}$ for easterly PGF events at lags of (a) -9 , (b) -6 , (c) -3 , (d) 0 , (e) 3, and (f) 6 days. Local values are significant at the $95 \%$ level inside the magenta contours and where vectors are shown.

geopotential height anomalies that intrude into the tropics from both hemispheres along the eastern coast of Africa as a positive tropical geopotential height anomaly expands eastward over the Indian Ocean. The flow around the subtropical gyres, denoted by the intraseasonal streamfunction, brings intraseasonal extratropical cyclones embedded in midlatitude wave trains equatorward from eastern Europe, western Asia, and southern Africa to reach the equator near eastern Africa. The intrusion of negative geopotential height anomalies over the east coast of Africa may influence the onset of MJO convection over the western Indian Ocean by accelerating upper-tropospheric easterly wind on the western side of a region of intraseasonal westerlies forming the flow pattern of upper-tropospheric mass divergence. Ridges then replace the zonally extended cyclones in the subtropics and grow in response to tropical convection, allowing for outflow from the enhanced convection of the MJO.
For this dominant group of easterly PGF events, there may be differences in both the structure and the path of the extratropical wave train such that individual events may not necessarily look like the composite. Moreover, specific events may have extratropical interactions from both Northern and Southern Hemispheres, either hemisphere, or neither hemisphere (with easterly PGF coming from local or tropically circumnavigating signals), which is a topic that needs to be explored further. Extratropical signals tend to be stronger in the Northern Hemisphere because of the analysis of boreal winter events; however, the Southern Hemisphere signals may not need to be as strong to have an impact because of the higher convective instability south of the equator. MJO forcing of intraseasonal extratropical waves, both upstream from the Pacific Ocean and downstream from the Indian Ocean, make coherence in signals from the Northern and Southern Hemispheres possible.

The results and proposed mechanisms agree with some of the recent modeling studies, which highlight 
the necessity of intraseasonal signals in the extratropical boundary conditions for MJO onset and strength (Ray and Zhang 2010; Ray et al. 2011; Zhao et al. 2013; Ray and Li 2013; Hall et al. 2017), though here we argue for the importance of signals in the upper troposphere as well as the lower troposphere. Furthermore, composites are consistent with the models that are able to trigger MJO-type signals via midlatitude disturbances (Lin et al. 2007; Pan and Li 2008).

As for the modeling studies that support the importance of circumnavigating signals over extratropical ones, the aquaplanet model of Maloney and Wolding (2015) would be unable to form the extratropical forcings suggested herein because of reductions made in the meridional SST gradient in the extratropics. Also, when Zhang et al. (2017) attribute external forcings as coming from the longitudinal boundary, the placement of the western boundary at $48^{\circ} \mathrm{E}$ lumps extratropical interactions over Africa (and the Western Hemisphere) with the tropically circumnavigating signal. On the other hand, this analysis does not rule out the potential influence of tropically circumnavigating or local signals for the onset of MJO activity in some MJO events. Instead, easterly time tendency along the west side of a region of intraseasonal westerlies may be influenced by circumnavigating and local forcings in addition to the extratropics, supporting upper-level divergence and a large-scale dynamical reduction in subsidence to help organize MJO convection. Other mechanisms besides easterly acceleration at upper levels may also help to drive the upward vertical velocity.

Acknowledgments. Funding was provided by the National Science Foundation Grant 1560627 to Paul Roundy. The OLR data were obtained from the NOAA PSD and the ECMWF Re-Analysis data were obtained from the NCAR RDA. Coding was implemented with NCAR Command Language (NCL; UCAR 2017). We thank Katherine Straub for feedback in earlier stages of this project, John Molinari for his suggestion to use Q-vector convergence, and three anonymous reviewers for their comments.

\section{REFERENCES}

Barlow, M., M. Wheeler, B. Lyon, and H. Cullen, 2005: Modulation of daily precipitation over southwest Asia by the Madden-Julian oscillation. Mon. Wea. Rev., 133, 3579-3594, https://doi.org/10.1175/MWR3026.1.

_- A. Hoell, and F. Colby, 2007: Examining the wintertime response to tropical convection over the Indian Ocean by modifying convective heating in a full atmospheric model. Geophys. Res. Lett., 34, L19702, https://doi.org/10.1029/ 2007 GL030043.
Benedict, J. J., and D. A. Randall, 2007: Observed characteristics of the MJO relative to maximum rainfall. J. Atmos. Sci., 64, 2332-2354, https://doi.org/10.1175/JAS3968.1.

Bladé, I., and D. L. Hartmann, 1993: Tropical intraseasonal oscillations in a simple nonlinear model. J. Atmos. Sci., 50, 2922-2939, https://doi.org/10.1175/1520-0469(1993)050<2922:TIOIAS > 2.0.CO;2.

Davies-Jones, R., 1991: The frontogenetical forcing of secondary circulations. Part I: The duality and generalization of the Q vector. J. Atmos. Sci., 48, 497-509, https://doi.org/10.1175/ 1520-0469(1991)048<0497:TFFOSC > 2.0.CO;2.

Dee, D. P., and Coauthors, 2011: The ERA-Interim reanalysis: Configuration and performance of the data assimilation system. Quart. J. Roy. Meteor. Soc., 137, 553-597, https://doi.org/ 10.1002/qj.828.

Duchon, C. E., 1979: Lanczos filtering in one and two dimensions. J. Appl. Meteor., 18, 1016-1022, https://doi.org/10.1175/1520-0450(1979) 018<1016:LFIOAT $>2.0$. CO;2.

Gill, A. E., 1980: Some simple solutions for heat-induced tropical circulation. Quart. J. Roy. Meteor. Soc., 106, 447-462, https:// doi.org/10.1002/qj.49710644905.

Hall, N. M. J., S. Thibaut, and P. Marchesiello, 2017: Impact of the observed extratropics on climatological simulations of the MJO in a tropical channel model. Climate Dyn., 48, 2541-2555, https://doi.org/10.1007/s00382-016-3221-5.

Hogan, E., A. Shelly, and P. Xavier, 2015: The observed and modelled influence of the Madden-Julian oscillation on East African rainfall. Meteor. Appl., 22, 459-469, https://doi.org/ 10.1002/met.1475.

Hohenegger, C., and B. Stevens, 2012: Preconditioning deep convection with cumulus congestus. J. Atmos. Sci., 70, 448-464, https://doi.org/10.1175/JAS-D-12-089.1.

Hoskins, B. J., I. Draghici, and H. C. Davies, 1978: A new look at the $\omega$-equation. Quart.J. Roy. Meteor. Soc., 104, 31-38, https:// doi.org/10.1002/qj.49710443903.

Hsu, H.-H., B. J. Hoskins, and F.-F. Jin, 1990: The 1985/86 intraseasonal oscillation and the role of the extratropics. J. Atmos. Sci., 47, 823-839, https://doi.org/10.1175/1520-0469(1990) 047<0823:TIOATR $>2.0 . \mathrm{CO} ; 2$.

Jeong, J.-H., C.-H. Ho, B.-M. Kim, and W.-T. Kwon, 2005: Influence of the Madden-Julian oscillation on wintertime surface air temperature and cold surges in east Asia. J. Geophys. Res., 110, D11104, https://doi.org/10.1029/2004JD005408.

Kiladis, G. N., C. D. Thorncroft, and N. M. J. Hall, 2006: Threedimensional structure and dynamics of African easterly waves. Part I: Observations. J. Atmos. Sci., 63, 2212-2230, https://doi.org/10.1175/JAS3741.1.

_ J. Dias, K. H. Straub, M. C. Wheeler, S. N. Tulich, K. Kikuchi, K. M. Weickmann, and M. J. Ventrice, 2014: A comparison of OLR and circulation-based indices for tracking the MJO. Mon. Wea. Rev., 142,1697-1715, https://doi.org/10.1175/MWR-D-13-00301.1.

Liebmann, B., and C. A. Smith, 1996: Description of a complete (interpolated) outgoing longwave radiation datasets. Bull. Amer. Meteor. Soc., 77, 1275-1277.

Lin, H., G. Brunet, and J. Derome, 2007: Intraseasonal variability in a dry atmospheric model. J. Atmos. Sci., 64, 2422-2441, https://doi.org/10.1175/JAS3955.1.

Lin, J.-L., M. Zhang, and B. Mapes, 2005: Zonal momentum budget of the Madden-Julian oscillation: The source and strength of equivalent linear damping. J. Atmos. Sci., 62, 2172-2188, https://doi.org/10.1175/JAS3471.1.

Ma, D., and Z. Kuang, 2016: A mechanism-denial study on the Madden-Julian oscillation with reduced interference from 
mean state changes. Geophys. Res. Lett., 43, 2989-2997, https://doi.org/10.1002/2016GL067702.

Maloney, E. D., and B. O. Wolding, 2015: Initiation of an intraseasonal oscillation in an aquaplanet general circulation model. J. Adv. Model. Earth Syst., 7, 1956-1976, https://doi.org/ 10.1002/2015MS000495.

Matthews, A. J., and G. N. Kiladis, 1999: The tropical-extratropical interaction between high-frequency transients and the MaddenJulian oscillation. Mon. Wea. Rev., 127, 661-677, https://doi.org/ 10.1175/1520-0493(1999)127<0661:TTEIBH>2.0.CO;2.

McTaggart-Cowan, R., G. D. Deane, L. F. Bosart, C. A. Davis, and T. J. Galarneau Jr., 2008: Climatology of tropical cyclogenesis in the North Atlantic (1948-2004). Mon. Wea. Rev., 136, 1284-1304, https://doi.org/10.1175/2007MWR2245.1.

Molinari, J., and D. Vollaro, 2012: A subtropical cyclonic gyre associated with interactions of the MJO and the midlatitude jet. Mon. Wea. Rev., 140, 343-357, https://doi.org/10.1175/MWR-D-11-00049.1.

North, G. R., T. L. Bell, R. F. Cahalan, and F. J. Moeng, 1982: Sampling errors in the estimation of empirical orthogonal functions. Mon. Wea. Rev., 110, 699-706, https://doi.org/10.1175/1520-0493(1982) $110<0699:$ SEITEO $>2.0 . \mathrm{CO} ; 2$.

Pan, L.-L., and T. Li, 2008: Interactions between the tropical ISO and midlatitude low-frequency flow. Climate Dyn., 31, 375-388, https://doi.org/10.1007/s00382-007-0272-7.

Powell, S. W., and R. A. Houze Jr., 2013: The cloud population and onset of the Madden-Julian oscillation over the Indian Ocean during DYNAMO-AMIE. J. Geophys. Res. Atmos., 118, 11 979-11 995, https://doi.org/10.1002/2013JD020421.

$\longrightarrow$, and - 2015: Effect of dry large-scale vertical motions on initial MJO convective onset. J. Geophys. Res. Atmos., 120, 4783-4805, https://doi.org/10.1002/2014JD022961.

Ray, P., and C. Zhang, 2010: A case study of the mechanics of extratropical influence on the initiation of the Madden-Julian oscillation. J. Atmos. Sci., 67, 515-528, https://doi.org/10.1175/2009JAS3059.1.

— tratropics on the MJO and its relationship with the mean state. J. Atmos. Sci., 70, 876-893, https://doi.org/10.1175/JAS-D-12-0153.1.

, C. Zhang, M. W. Moncrieff, J. Dudhia, J. M. Caron, L. R. Leung, and C. Bruyere, 2011: Role of the atmospheric mean state on the initiation of the Madden-Julian oscillation in a tropical channel model. Climate Dyn., 36,161-184, https://doi.org/ 10.1007/s00382-010-0859-2.

Roundy, P. E., 2014: Some aspects of Western Hemisphere circulation and the Madden-Julian oscillation. J. Atmos. Sci., 71, 2027-2039, https://doi.org/10.1175/JAS-D-13-0210.1.
Sakaeda, N., and P. E. Roundy, 2015: The development of uppertropospheric wind over the Western Hemisphere in association with MJO convective initiation. J. Atmos. Sci., 72, 3138-3160, https://doi.org/10.1175/JAS-D-14-0293.1.

_ and - 2016: The development of upper-tropospheric geopotential height anomaly in the Western Hemisphere during MJO convective initiations. Quart. J. Roy. Meteor. Soc., 142, 942-956, https://doi.org/10.1002/qj.2696.

Schreck, C. J., III, L. Shi, J. P. Kossin, and J. J. Bates, 2013: Identifying the MJO, equatorial waves, and their impacts using 32 years of HIRS upper-tropospheric water vapor. J. Climate, 26, 1418-1431, https://doi.org/10.1175/JCLI-D12-00034.1.

Straub, K. H., 2013: MJO initiation in the real-time multivariate MJO index. J. Climate, 26,1130-1151, https://doi.org/10.1175/ JCLI-D-12-00074.1.

UCAR, 2017: The NCAR command language. UCAR, https:// doi.org/10.5065/D6WD3XH5.

Wang, L., K. Kodera, and W. Chen, 2012: Observed triggering of tropical convection by a cold surge: Implications for MJO initiation. Quart. J. Roy. Meteor. Soc., 138, 1740-1750, https:// doi.org/10.1002/qj.1905.

Wheeler, M. C., and G. N. Kiladis, 1999: Convectively coupled equatorial waves: Analysis of clouds and temperature in the wavenumber-frequency domain. J. Atmos. Sci., 56, 374-399, https://doi.org/10.1175/1520-0469(1999)056<0374:CCEWAO> 2.0.CO;2.

- and H. H. Hendon, 2004: An all-season real-time multivariate MJO index: Development of an index for monitoring and prediction. Mon. Wea. Rev., 132, 1917-1932, https://doi.org/ 10.1175/1520-0493(2004)132<1917:AARMMI>2.0.CO;2.

Zhang, C., 2005: Madden-Julian oscillation. Rev. Geophys., 43, RG2003, https://doi.org/10.1029/2004RG000158.

Zhang, F., S. Taraphdar, and S. Wang, 2017: The role of global circumnavigating mode in the MJO initiation and propagation. J. Geophys. Res. Atmos., 122, 5837-5856, https://doi.org/ 10.1002/2016JD025665.

Zhao, C., T. Li, and T. Zhou, 2013: Precursor signals and processes associated with MJO initiation over the tropical Indian Ocean. J. Climate, 26, 291-307, https://doi.org/10.1175/JCLI-D-1200113.1.

Zhou, L., A. H. Sobel, and R. Murtugudde, 2012: Kinetic energy budget for the Madden-Julian oscillation in a multiscale framework. J. Climate, 25, 5386-5403, https://doi.org/10.1175/ JCLI-D-11-00339.1. 